\title{
A media-based assessment of damage and ground motions from the January 26th, $2001 M 7.6$ Bhuj, India earthquake
}

\author{
Susan E Hough ${ }^{1}$, Stacey Martin ${ }^{2}$, Roger Bilham ${ }^{3}$ and Gail M Atkinson \\ ${ }^{1}$ United States Geological Survey, Pasadena, California. \\ ${ }^{2}$ Nowrosjee Wadia College, Pune, India. \\ ${ }^{3}$ University of Colorado, Boulder, Colorado. \\ ${ }^{4}$ Ottawa, Canada.
}

We compiled available news and internet accounts of damage and other effects from the 26th January, 2001, Bhuj earthquake, and interpreted them to obtain modified Mercalli intensities at over 200 locations throughout the Indian subcontinent. These values are used to map the intensity distribution using a simple mathematical interpolation method. The maps reveal several interesting features. Within the Kachchh region, the most heavily damaged villages are concentrated towards the western edge of the inferred fault, consistent with western directivity. Significant sedimentinduced amplification is also suggested at a number of locations around the Gulf of Kachchh to the south of the epicenter. Away from the Kachchh region intensities were clearly amplified significantly in areas that are along rivers, within deltas, or on coastal alluvium such as mud flats and salt pans. In addition we use fault rupture parameters inferred from teleseismic data to predict shaking intensity at distances of $0-1000 \mathrm{~km}$. We then convert the predicted hard rock ground motion parameters to MMI using a relationship (derived from internet-based intensity surveys) that assigns MMI based on the average effects in a region. The predicted MMIs are typically lower by 1-2 units than those estimated from news accounts. This discrepancy is generally consistent with the expected effect of sediment response, but it could also reflect other factors such as a tendency for media accounts to focus on the most dramatic damage, rather than the average effects. Our modeling results also suggest, however, that the Bhuj earthquake generated more high-frequency shaking than is expected for earthquakes of similar magnitude in California, and may therefore have been especially damaging.

\section{Introduction}

The M7.6 Bhuj earthquake occurred in the state of Gujarat, India at 03:16 GMT (8:16 am, local time) on January 26th, 2001 (figure 1). The event struck within the Kachchh peninsula near India's western coast and was felt over much of the Indian subcontinent. Damage in some parts of Gujarat was severe. Eyewitnesses reported that approximately one building in ten remained standing in Bhuj and Anjar, the closest large cities to the epicenter. Considerable damage was also reported in Hyderabad in southern Pakistan, while cities on the ancient
Indian craton at similar distances from the epicenter were not severely shaken. Although some multistorey concrete buildings completely collapsed in moderately shaken regions, many other structures remained intact, indicating that poor quality construction aggravated the damage. The Bhuj earthquake also generated substantial liquefaction and hydrological effects, including mud-volcanoes (e.g., Tuttle et al 2001a, 2001b), lateral spreading, and liquefaction in port cities.

Although instrumental recordings of the Bhuj earthquake are unfortunately scarce, isoseismal intensities provide an important data set. The

Keywords. Bhuj earthquake; intensity; ground motions. 


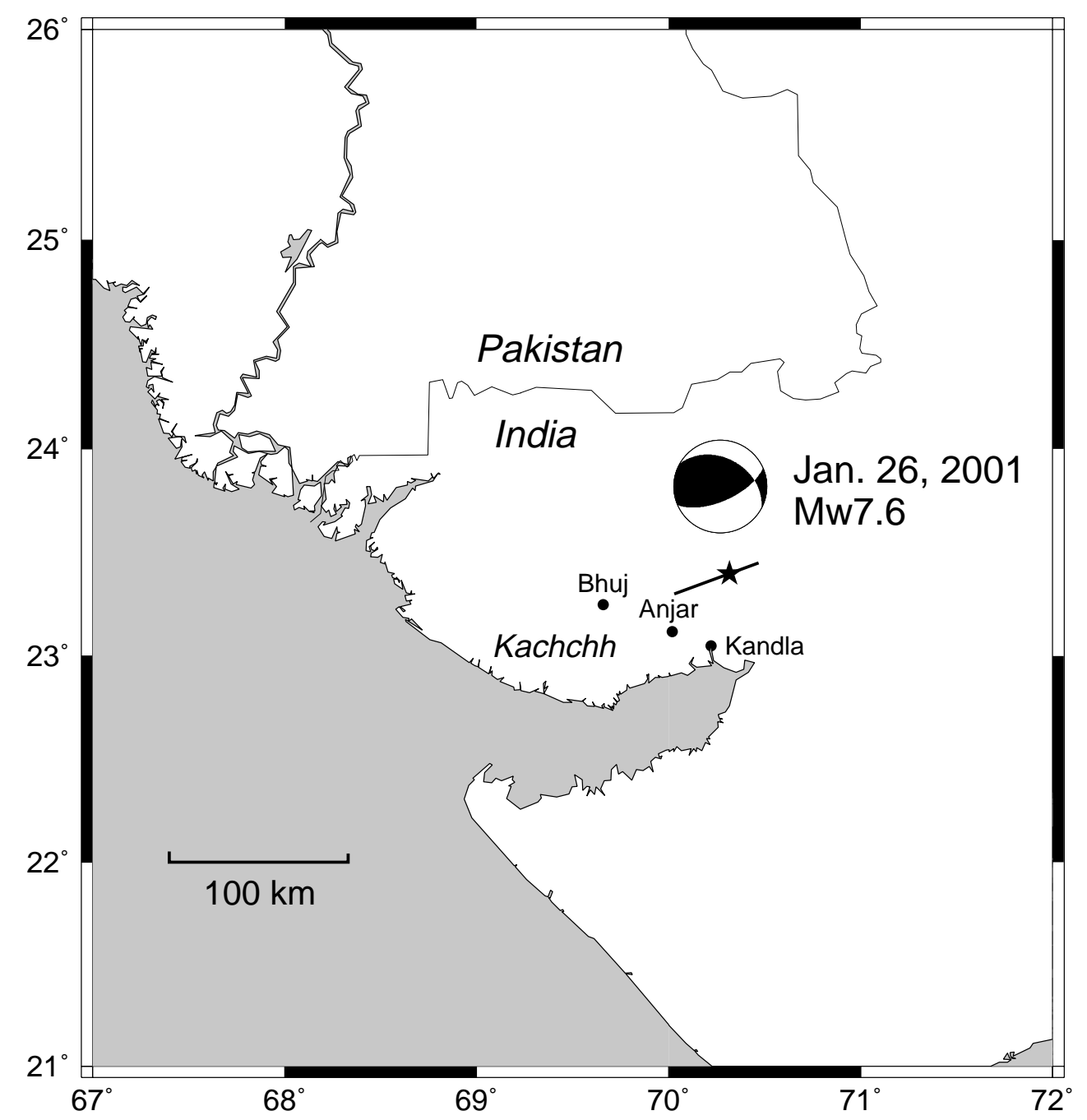

Figure 1. Map showing location of the 26th January, 2001 Bhuj, India earthquake within the Rann of Kachchh. The straight line shows a "pseudo-fault" with strike and length from Yagi and Kikuchi (2001). The focal mechanism corresponding to this solution is also shown. Preliminary aftershock relocations indicate a south-dipping rupture plane.

distribution of strong motion instruments in India is not adequate to calibrate directly the MMI values relative to physical ground motion parameters. However, the Bhuj earthquake was well-recorded at teleseismic distances. Intensity results from the Bhuj earthquake will thus be useful to better constrain the magnitude of historic Indian earthquakes (e.g., Ambraseys and Bilham 2000).

Extensive news articles were written in the early aftermath of the Bhuj earthquake and were published in both conventional newspapers and on the web. We compiled available accounts from reputable sources and interpreted them to obtain modified Mercalli intensity (MMI) values following conventional practice. Our final data set includes MMI values for nearly 200 sites throughout the Indian subcontinent, with the highest concentration of values within $300 \mathrm{~km}$ of Bhuj.

We anticipate that our results will eventually be supplanted by MMI maps determined from ground observations and conventional mail surveys. However, we proceeded with a determination of a "media-based intensity map" for two reasons. First, we believe the map does provide a good characterization of shaking effects throughout the subcontinent. But more importantly, we construct our MMI map based solely on media accounts so that the results can be compared to both media-based maps for earlier earthquakes and to the MMI distribution determined for the Bhuj earthquake using conventional ground- and mailbased surveys. These comparisons should provide useful insights into the nature of the biases that can result from determination of intensity distribution based only on news reports. Because such sources often provide the only source of information for older earthquakes (pre-1900, typically), the issue of "media biases" often looms large in the interpretation of intensity data for important historic earthquakes. Furthermore, it is likely that web and 
media-based assessments will become increasingly common in future large earthquakes world-wide.

\section{Isoseismal intensities}

Beginning in the immediate aftermath of the Bhuj earthquake, we compiled news accounts from traditional print media sources in the United States and India as well as internet-based sources. A summary of these reports, including their sources, is listed in table 1. From the available accounts, we assigned modified Mercalli intensities (e.g., Stover and Coffman 1993) based on the severity of shaking. In a few cases, news sources document that the event was not felt at a given location. In the Kachchh region, the most heavily damaged regions are generally assigned MMI values of IX-X, corresponding to heavy damage to masonry structures. Few values in excess of $\mathrm{X}$ are assigned, reflecting the paucity of accounts describing significant damage to modern, engineered structures. In the town of Sukhpur, however, one account describes a 10year old child being flung into the air. We assign MMI of XI-XII for this location.

Intensity values can be interpreted as point data; our results for the Bhuj earthquake are shown in figure 2. Typically, however, such data are used to define isoseismal contours. This approach is fraught with potential biases, as discussed at length by Hough et al (2000). In particular, any general approach to interpolation or contouring will not reflect the systematic dependence of ground motions on site geology. Ideally, knowledge of local geologic structure can provide important constraints, but such information was not available to us.

To map out the shaking distribution over the entire subcontinent, we employ a simple mathematical approach whereby the data are contoured using a continuous curvature gridding algorithm. A uniform grid of estimated intensity values, $I(x, y)$, is determined by solving the equation

$$
(1-T) \cdot L(L(I))+T \cdot L(I)=0,
$$

where $T$ is a tension factor between 0 and 1 , and $L$ indicates the Laplacian operator (see Wessel and Smith 1991). A tension factor of 0 yields the minimum curvature solution, which can produce minima and maxima away from constrained values. With a value of 1 , no minima or maxima occur away from control points. A tension factor of 1.0 is used to avoid introduction of extreme values not constrained by data (figure 3); the results are not very sensitive to the precise value chosen. Figure 4 presents a close-up view of the Kachchh region.

The intensity maps reveal several interesting features. The event was felt only lightly at the higher-elevation cities on Deccan lavas throughout central and southern India. Away from the Kachchh region, intensities were clearly amplified significantly in areas that are along rivers, within deltas, or on coastal alluvium. One example is the Narmada River Valley in the province of Madhya Pradesh, where MMI values as high as VI were reached at distances of over $600 \mathrm{~km}$. Significant site effects were also observed within Mumbai (Bombay). Most of the city experienced shaking at the MMI V level, but intensities up to VI-VII were reached at areas built on landfill in southern and central Mumbai as well as along Bombay Harbour.

Interesting features can be seen in the intensity distribution within the Kachchh region as well. The most heavily damaged villages are concentrated towards the western edge of the inferred fault, suggesting substantial western directivity from the epicenter. Some of the largest mud volcanoes were also documented in this region (Tuttle et al 2001b.) Significant sediment-induced amplification is also suggested at a number of locations around the Gulf of Kachchh, including Kandla (immediately south of the epicenter) and many of the villages on mud flats around the gulf.

The distribution of intensities in Kachchh are quite consistent with the spatial extent of liquefaction features as described by Tuttle et al (2001a, 2001b). In northern Kachchh the correspondence is not coincidental, as observations of liquefaction were used to assign some of the MMI values in some unpopulated areas. No liquefaction was observed in southwestern Kachchh, however, and the low MMI values in this region were assigned based on relatively light damage in this area.

\section{Predicted ground motions}

Although the Bhuj earthquake was not recorded by strong motion instruments, it was well-recorded at teleseismic distances (e.g., Yagi and Kikuchi 2001). We use a simplified source model determined from instrumental data to predict ground motions at local and regional distances using the finite fault method of Beresnev and Atkinson (1997). This analysis is complicated by the fact that neither the ground motions nor the fault parameters are wellconstrained. We therefore seek to investigate only the general consistency between the inferred and predicted ground motions.

Our fault model is based on the moment, rupture length, width, and strike from the results of Yagi and Kikuchi (2001), assuming a southdipping fault plane. Preliminary results (e.g., Yagi and Kikuchi 2001) suggest that the fault occurred on a thrust fault that did not break the 


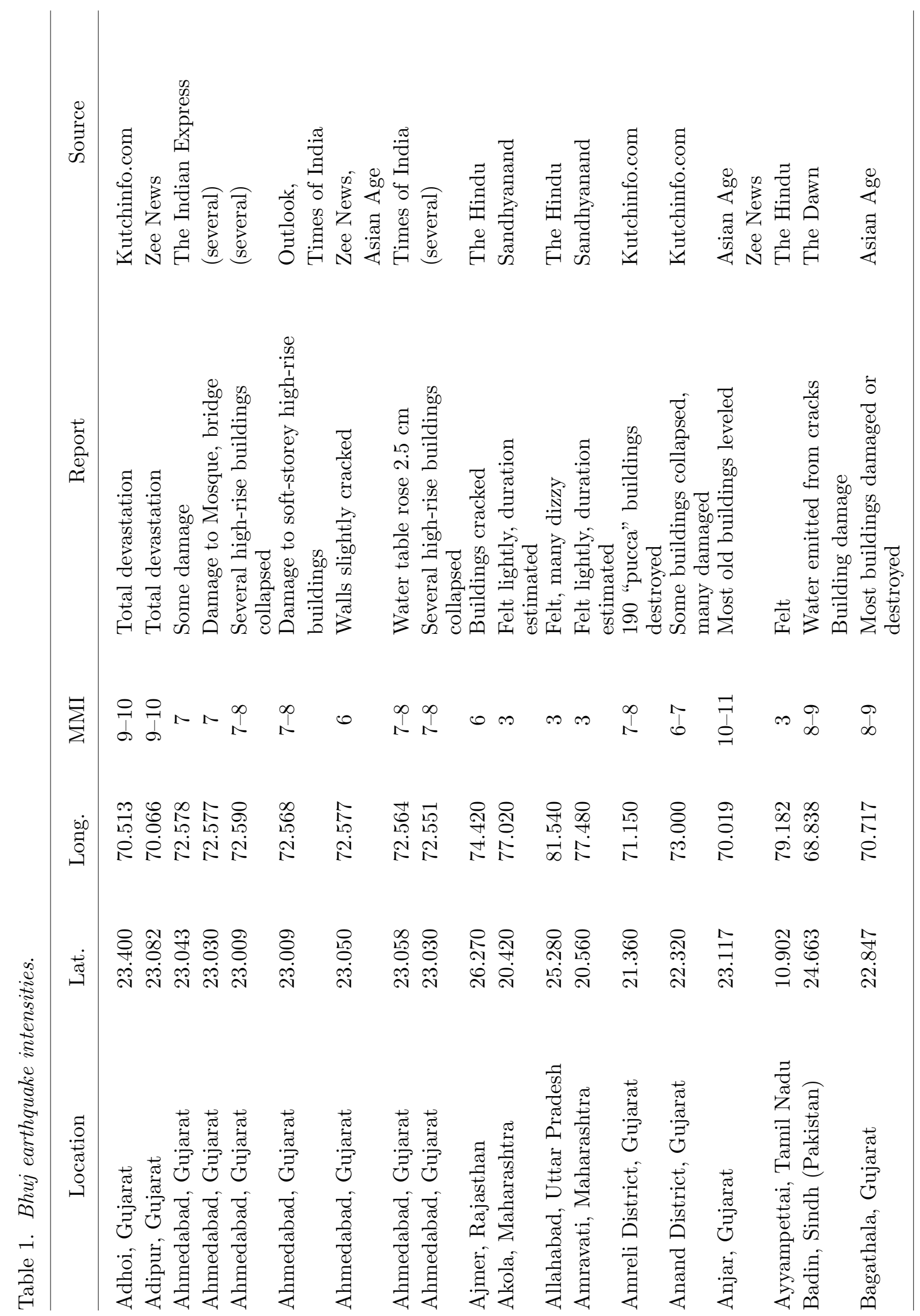




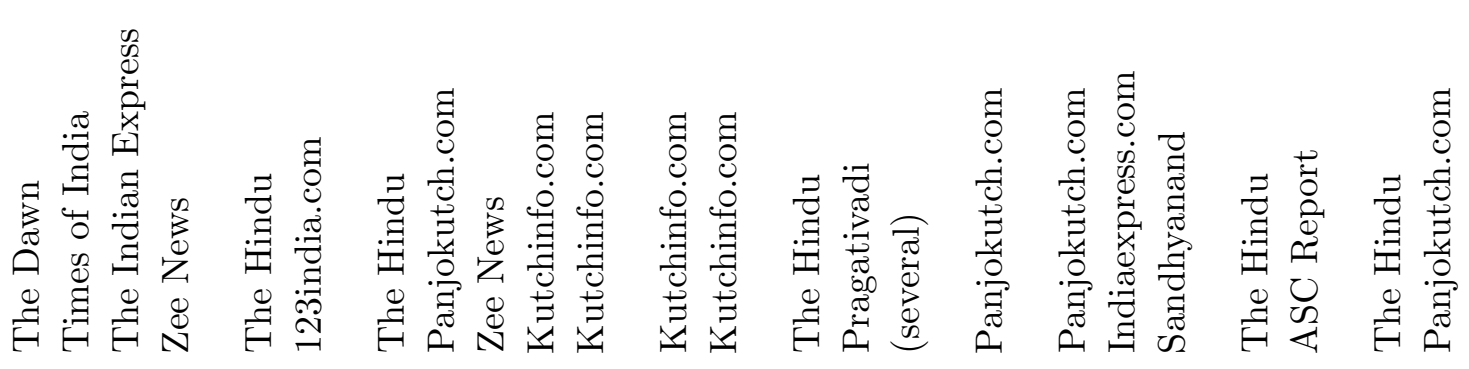

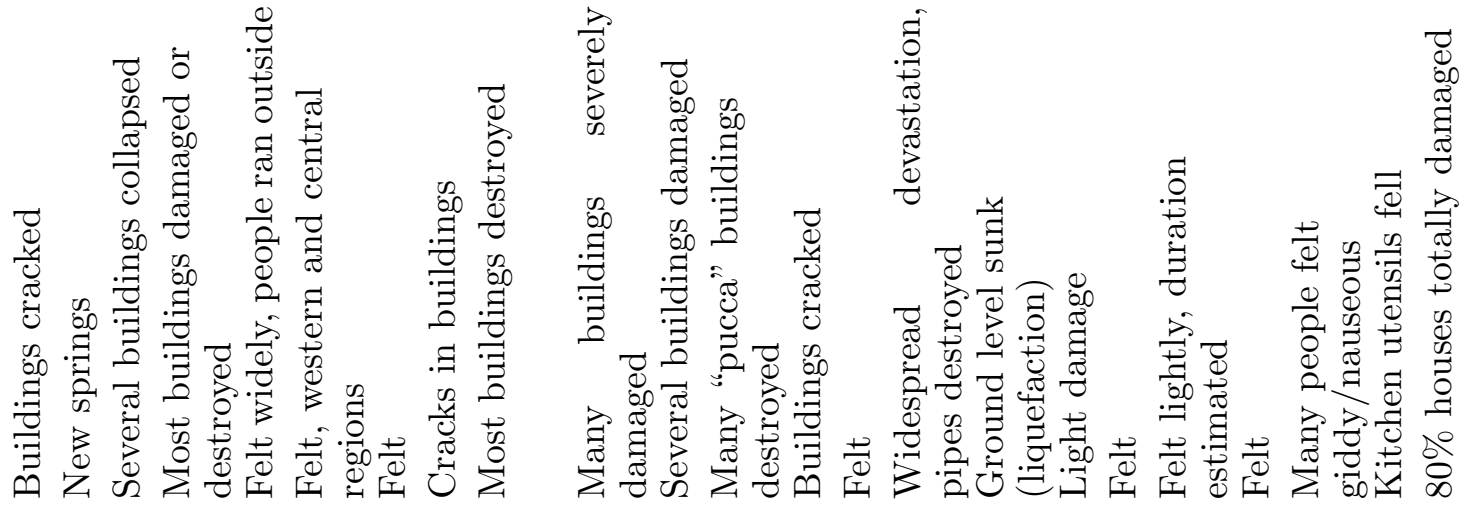

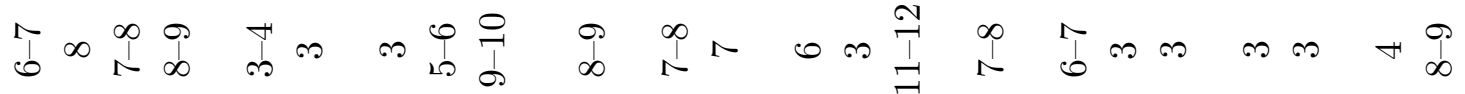

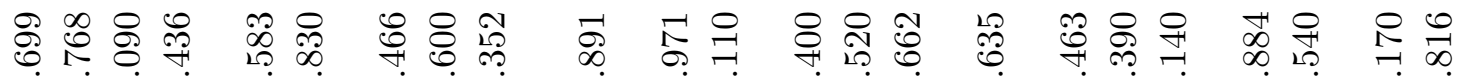
近这

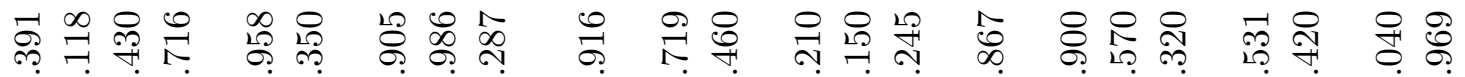
ลิ่
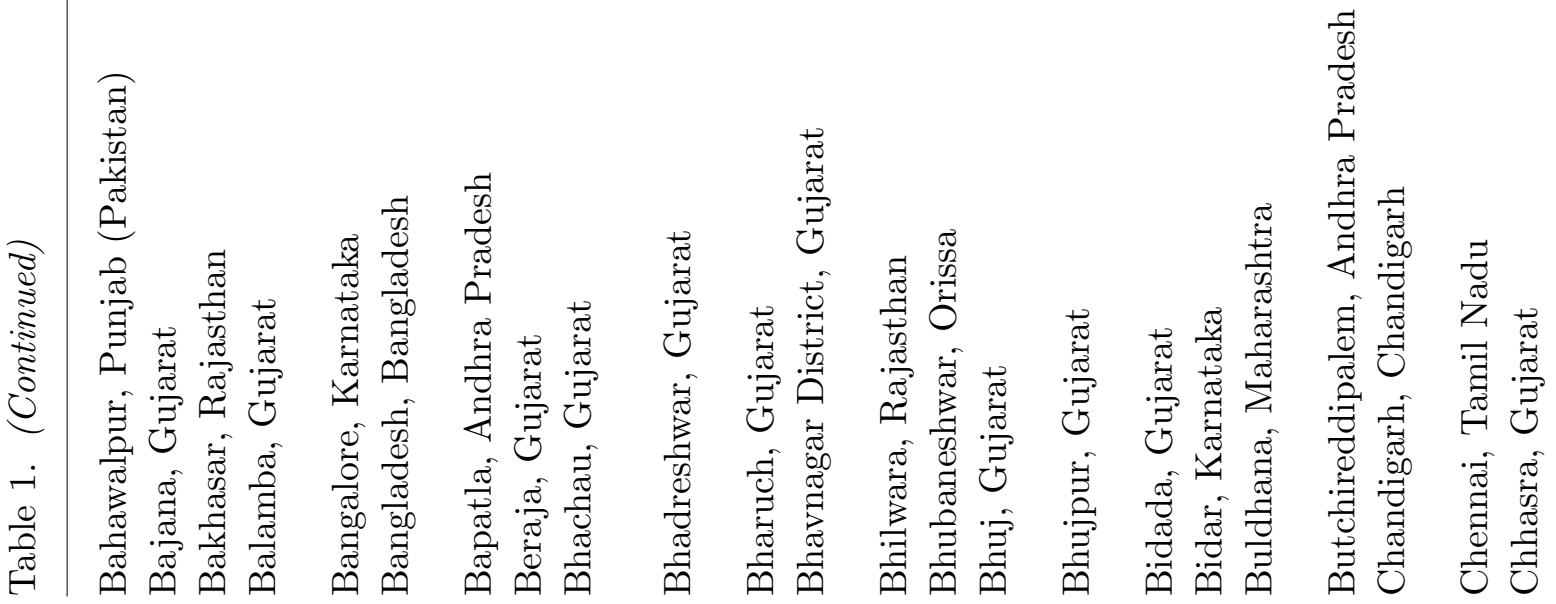


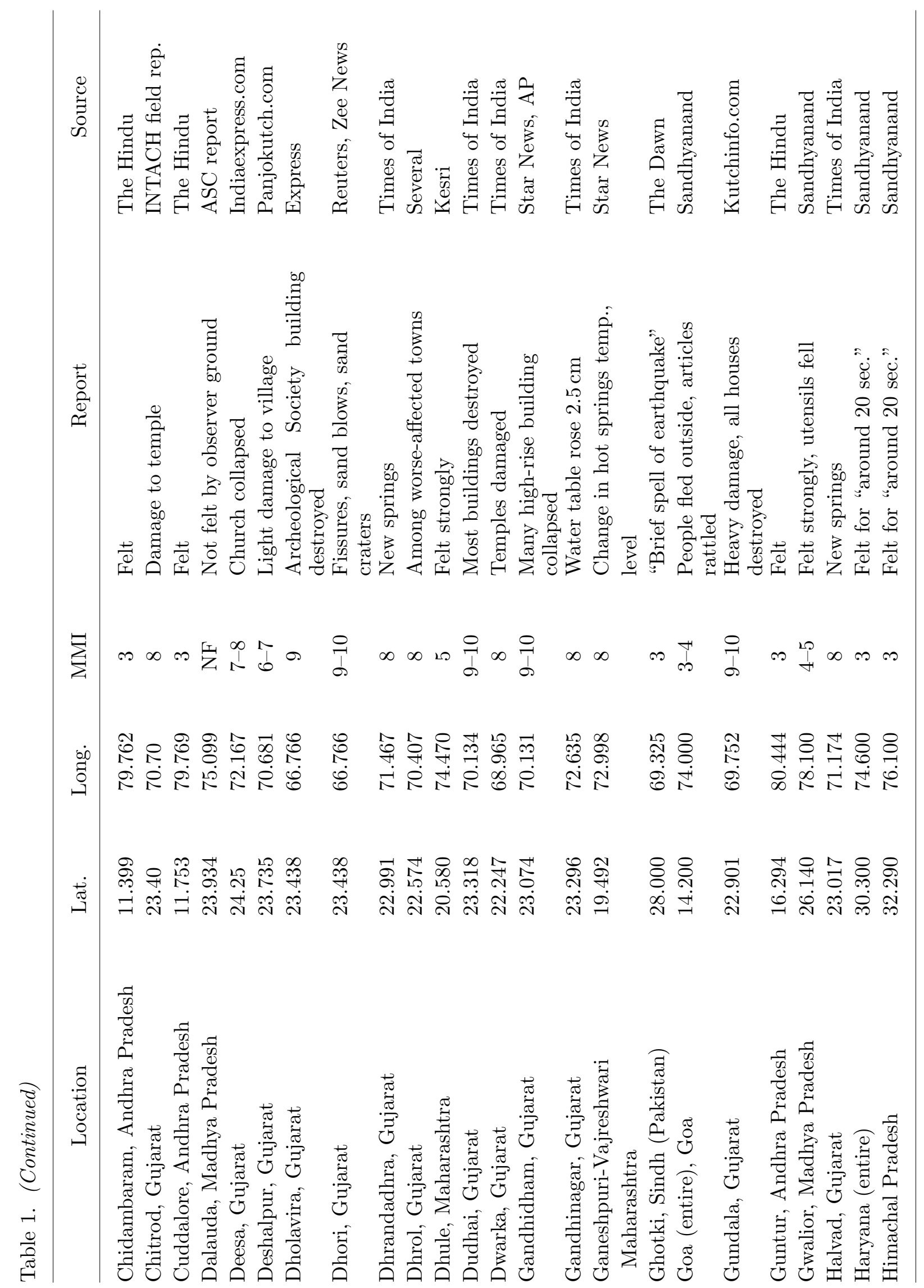




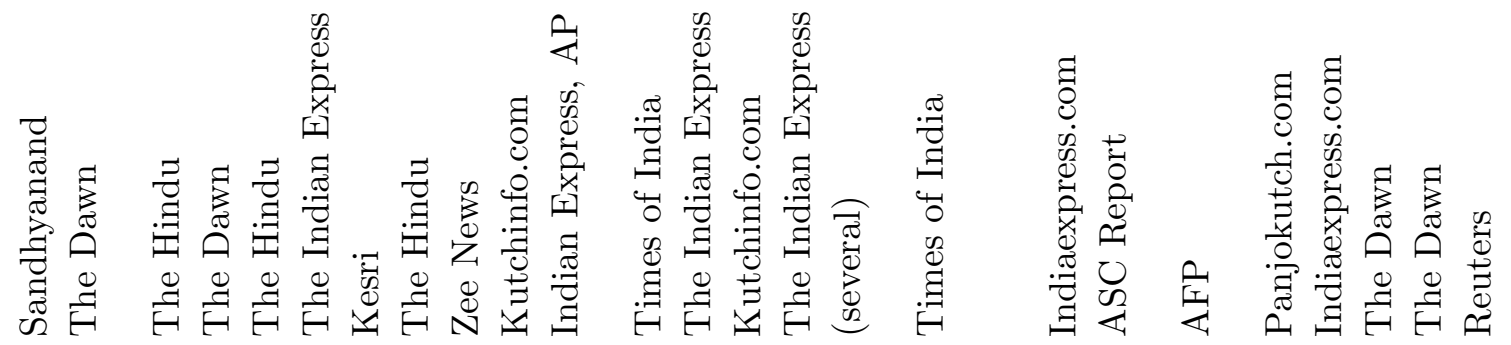

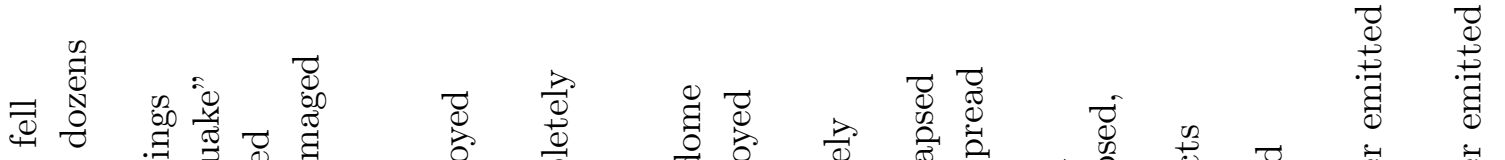

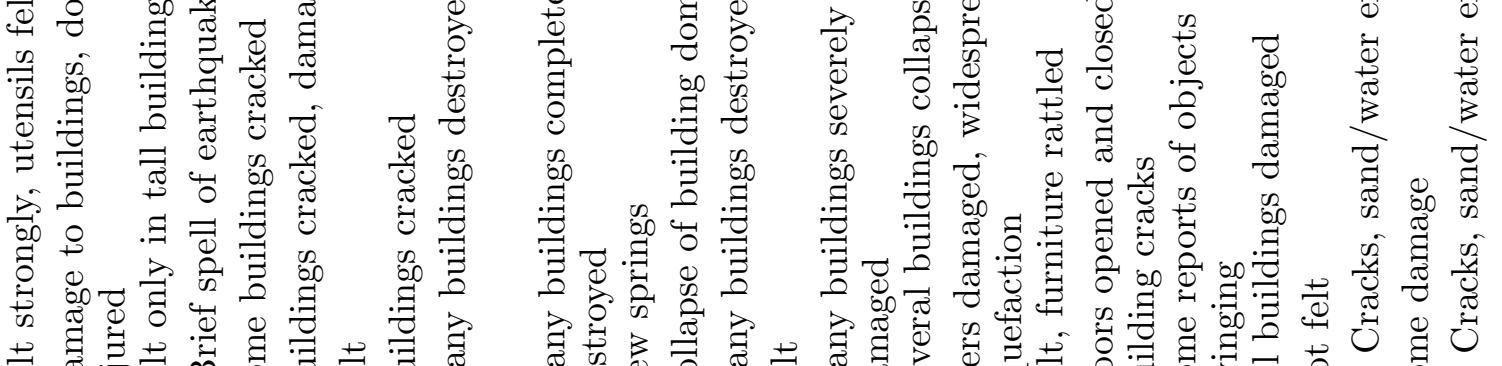

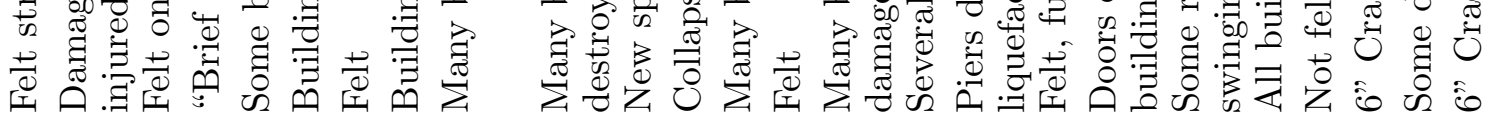

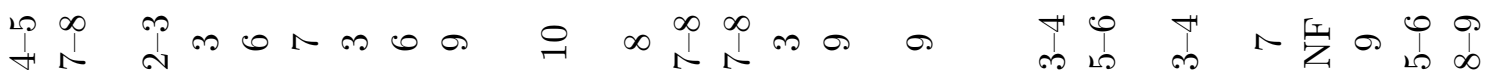

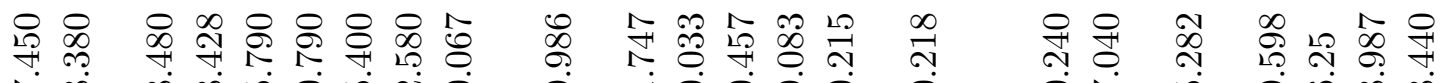
숭

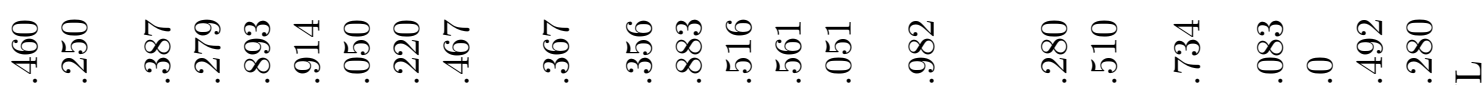

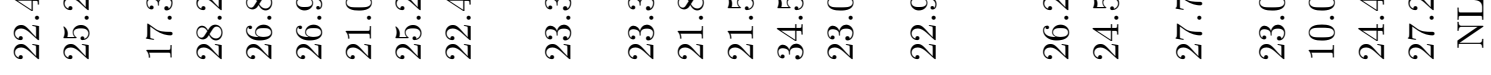
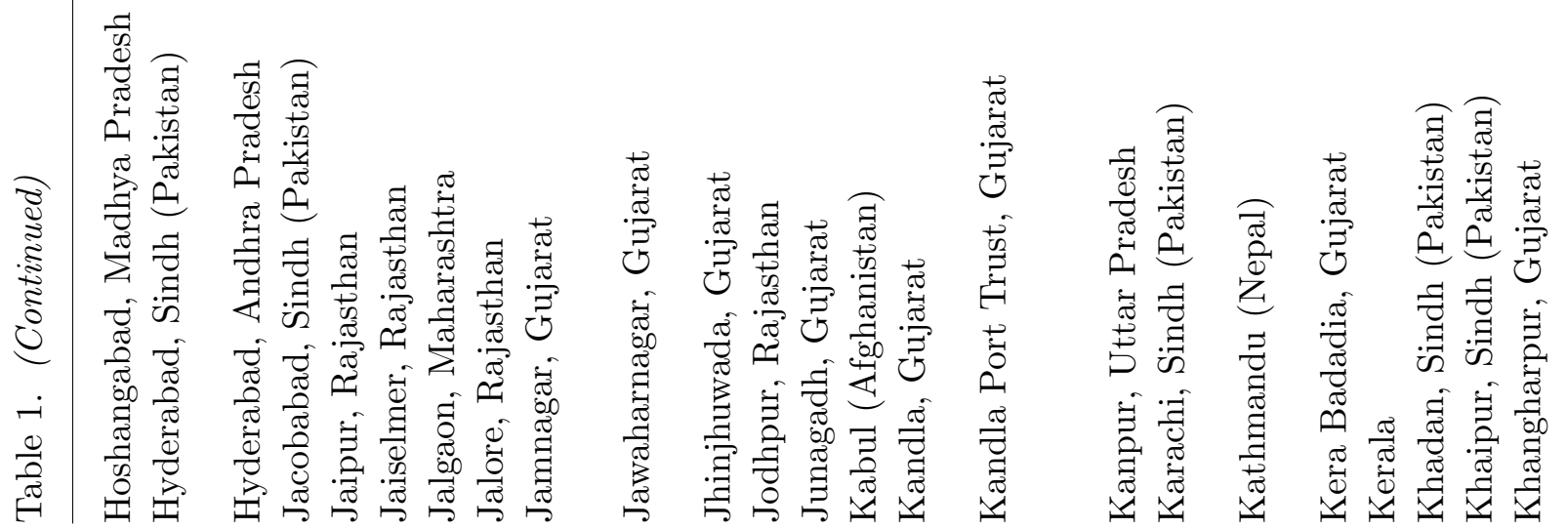


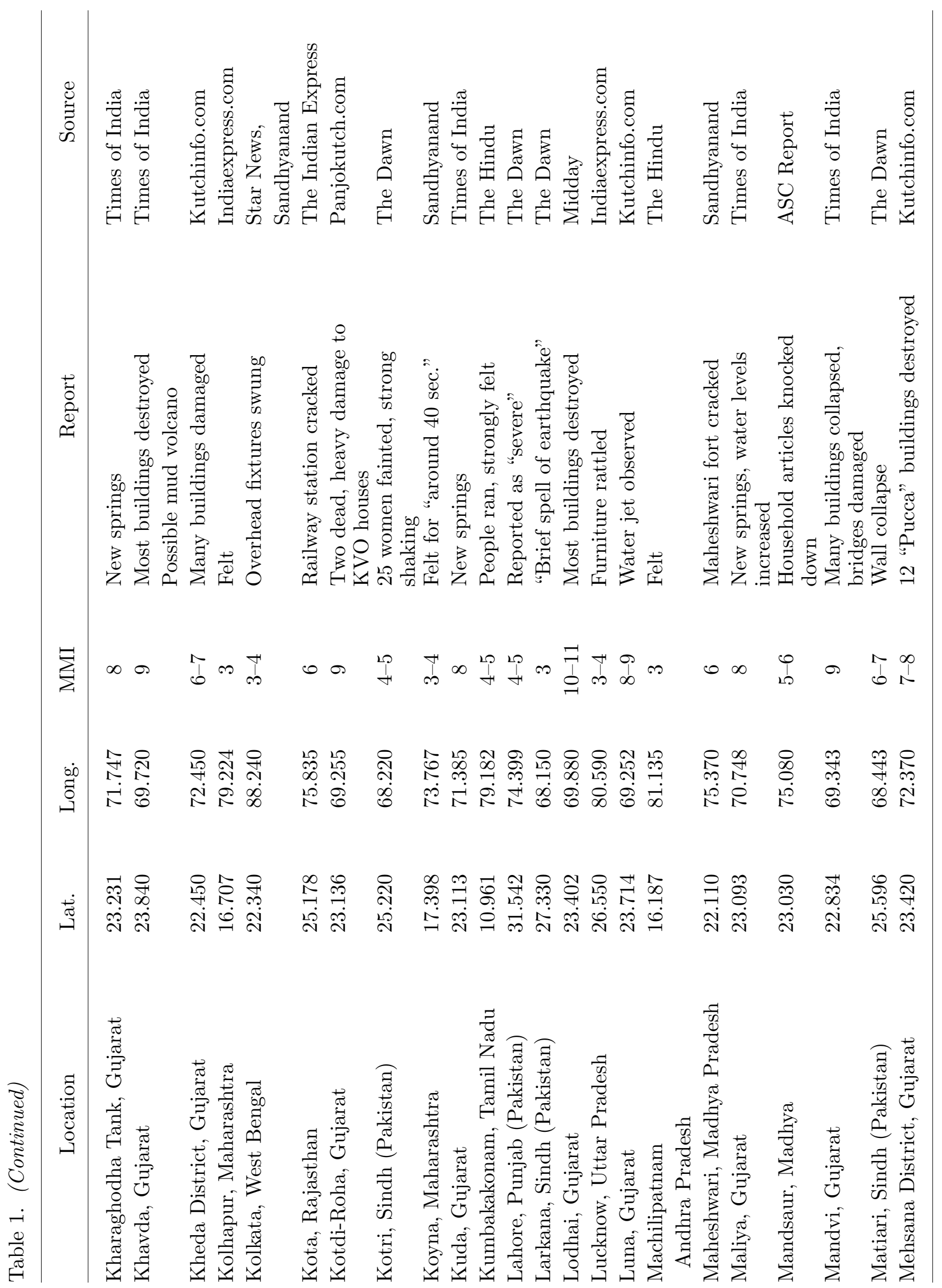




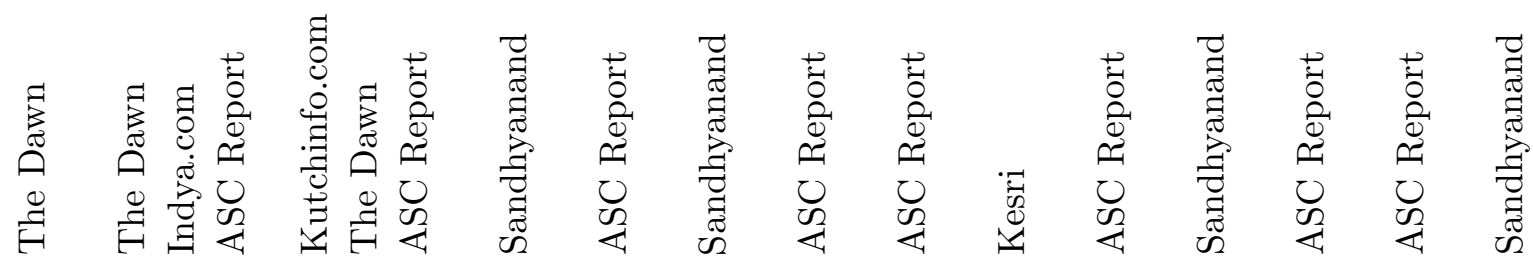

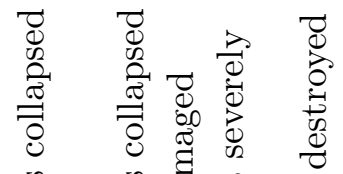

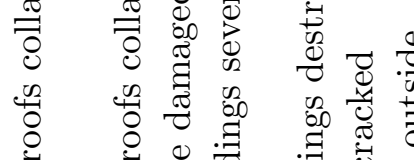

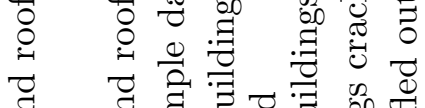

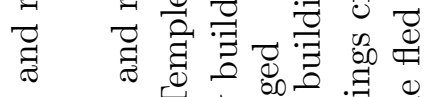

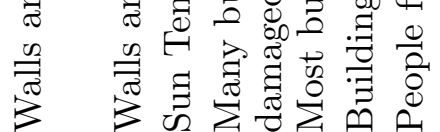

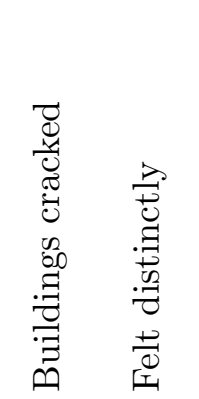

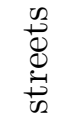

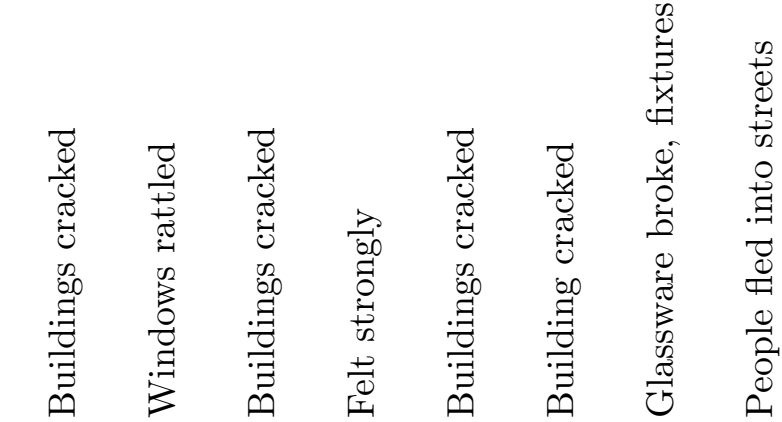

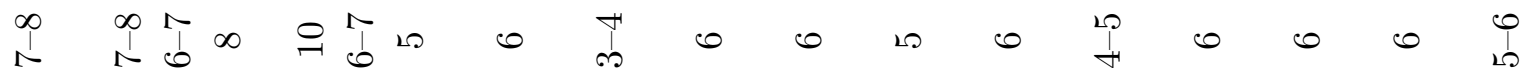

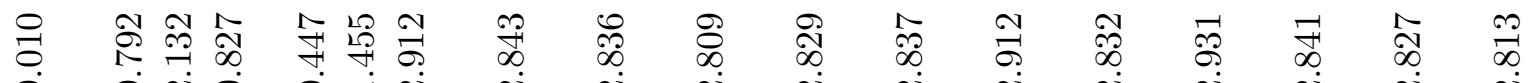

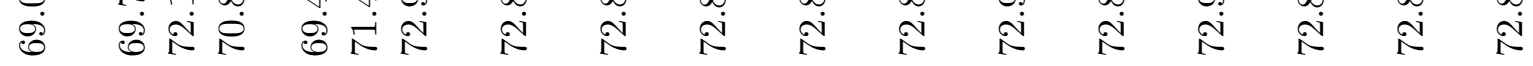

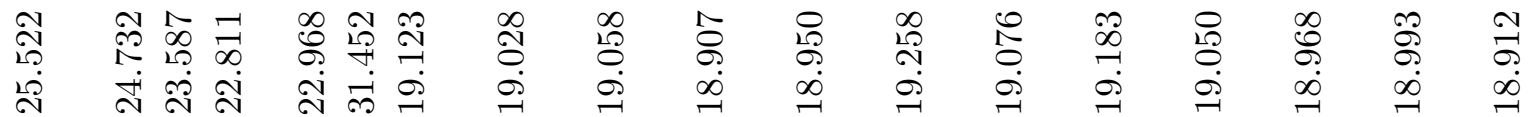<smiles>C#CC1CC1C1CC1</smiles>

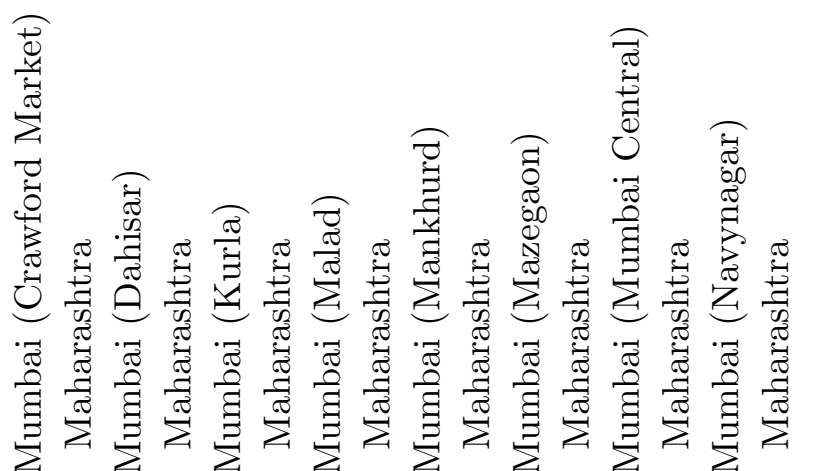




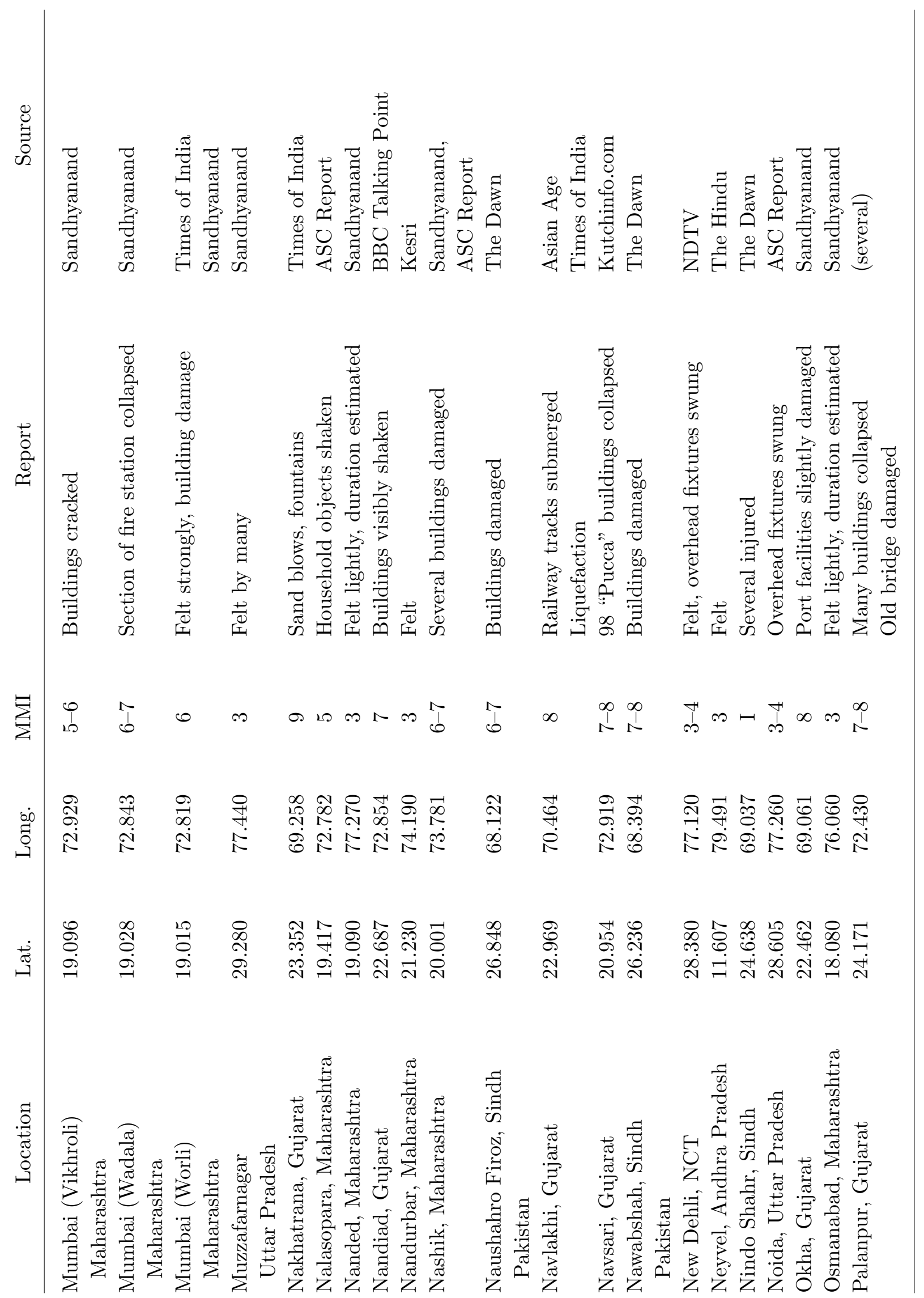


g

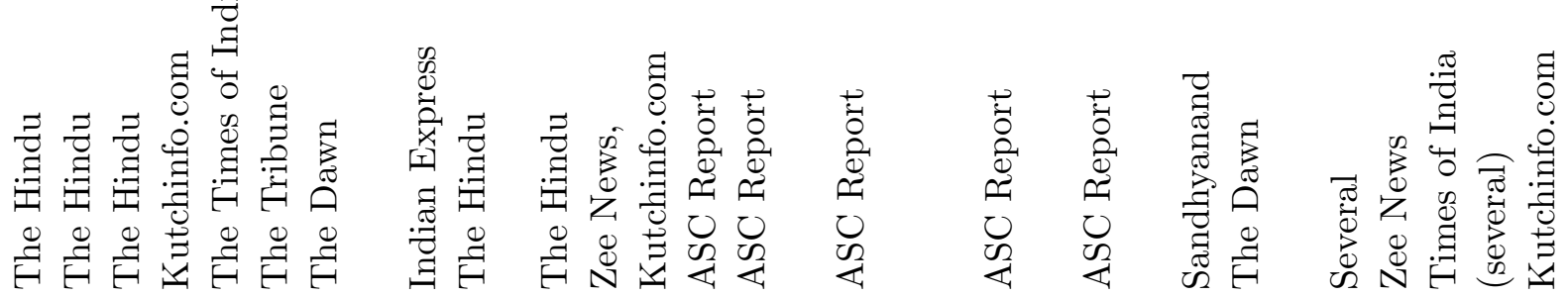

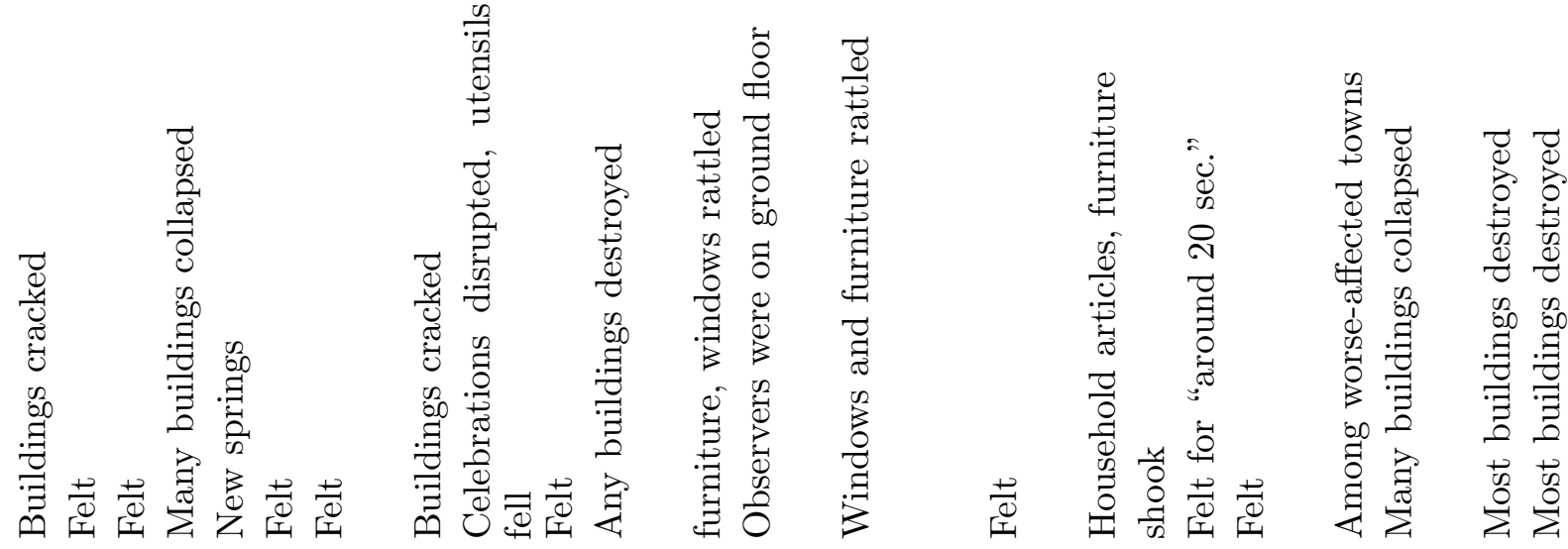
o

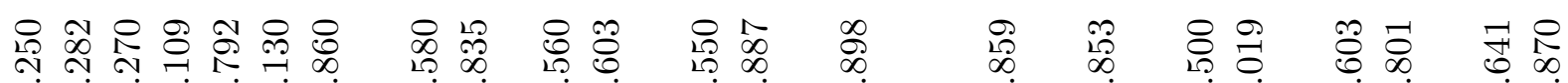

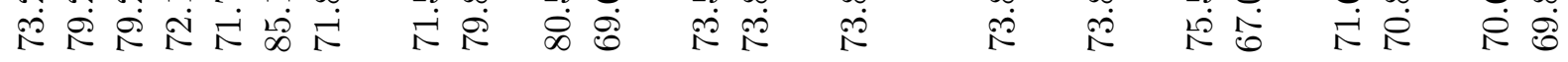

\&유

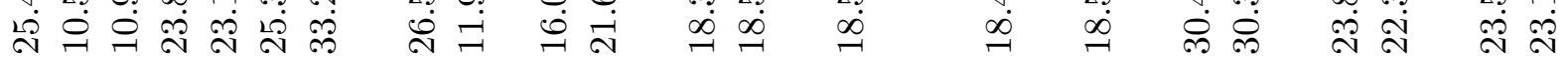

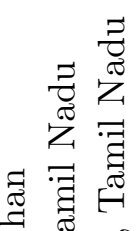

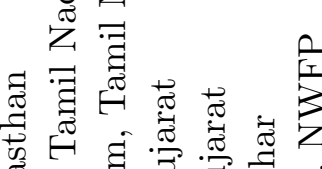

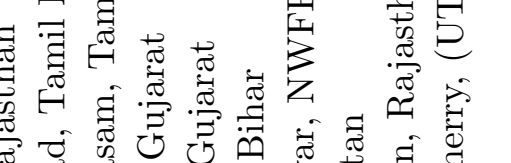

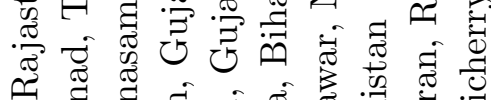

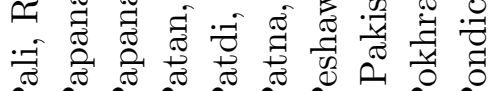

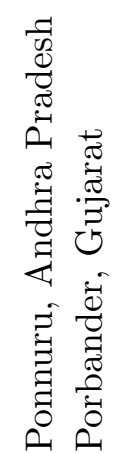

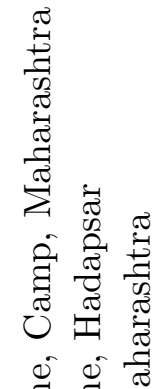

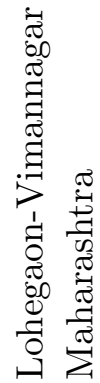

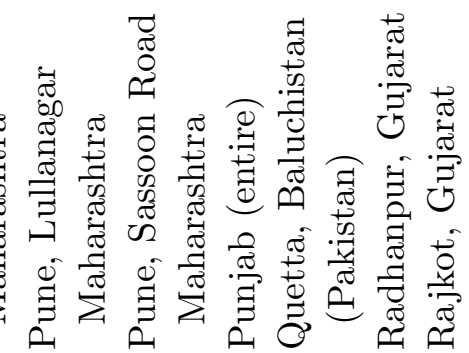

茪荢

కా

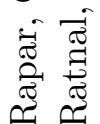




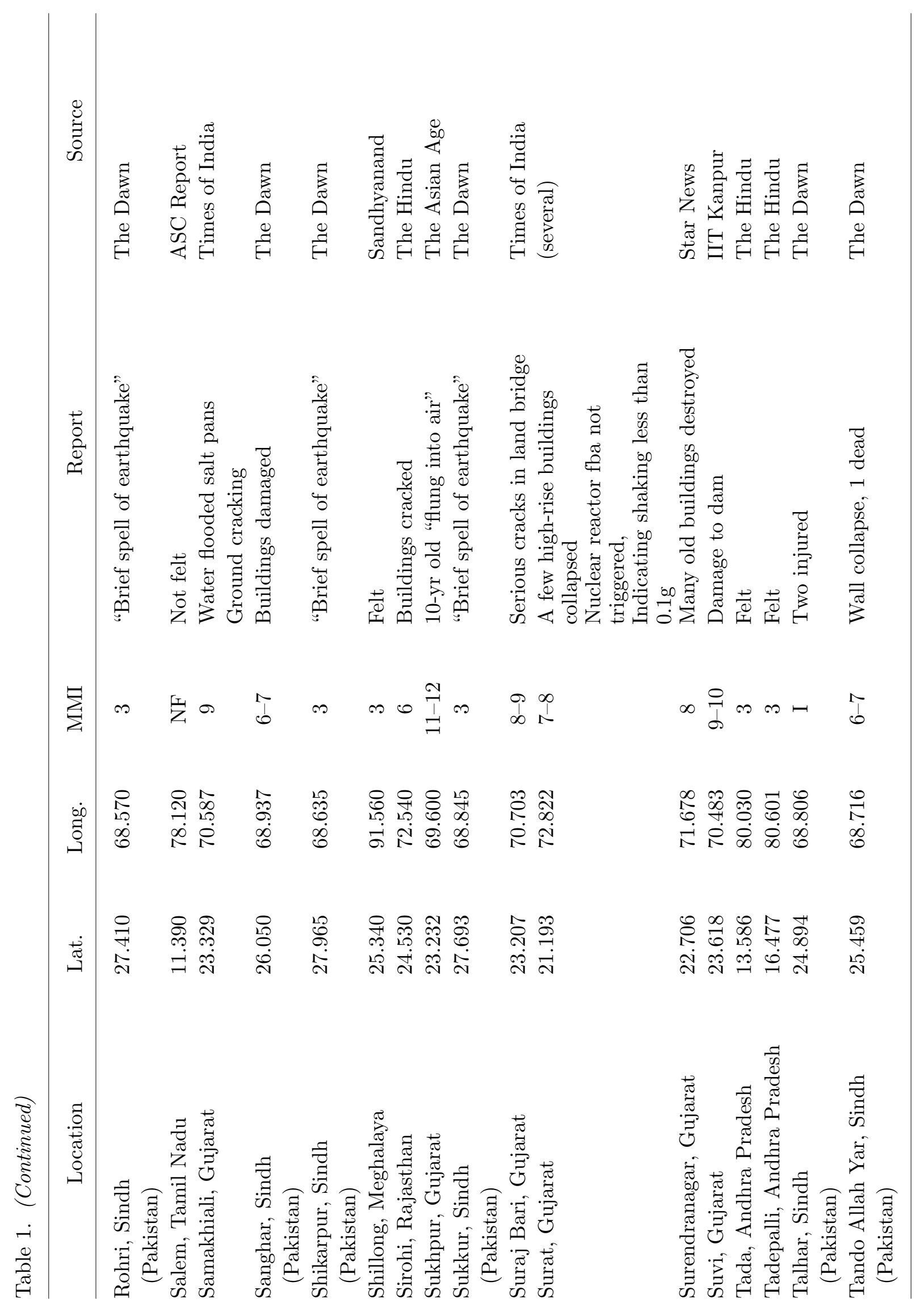




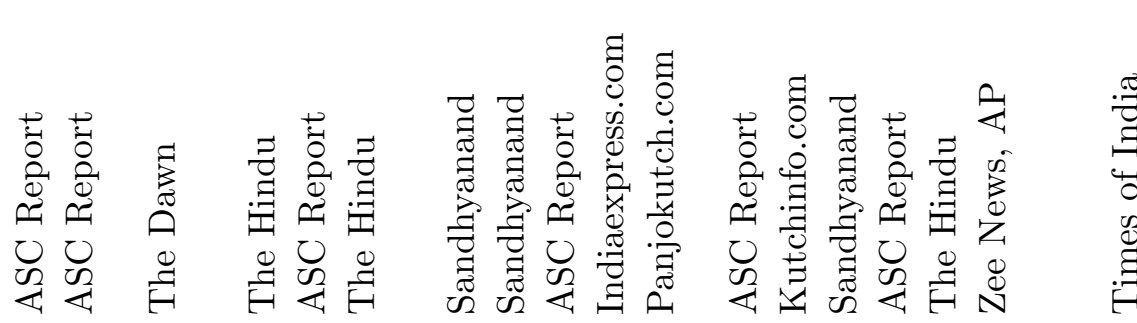

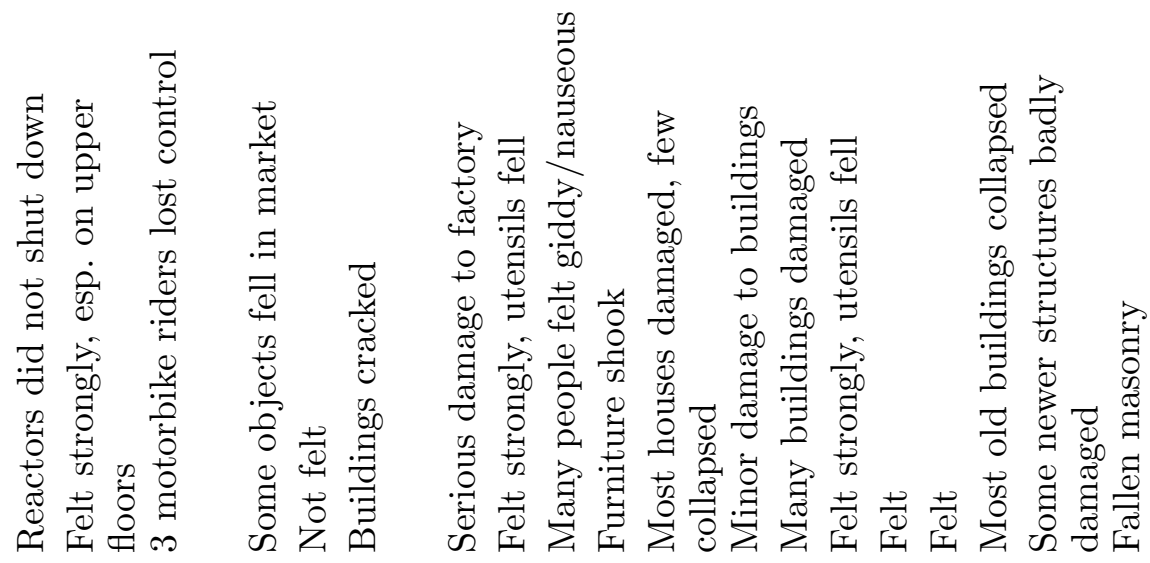

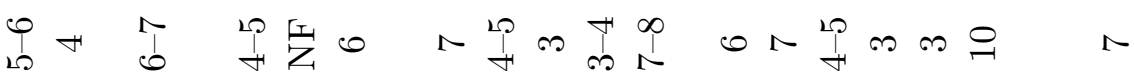

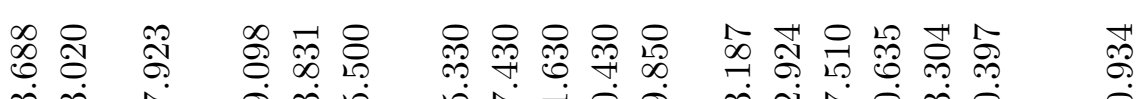
๙ิ

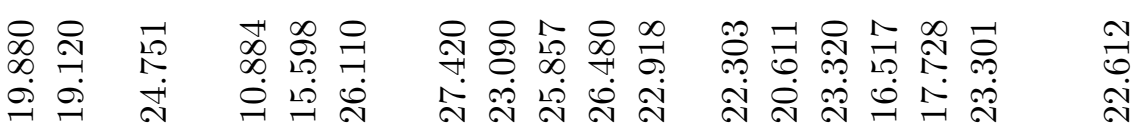




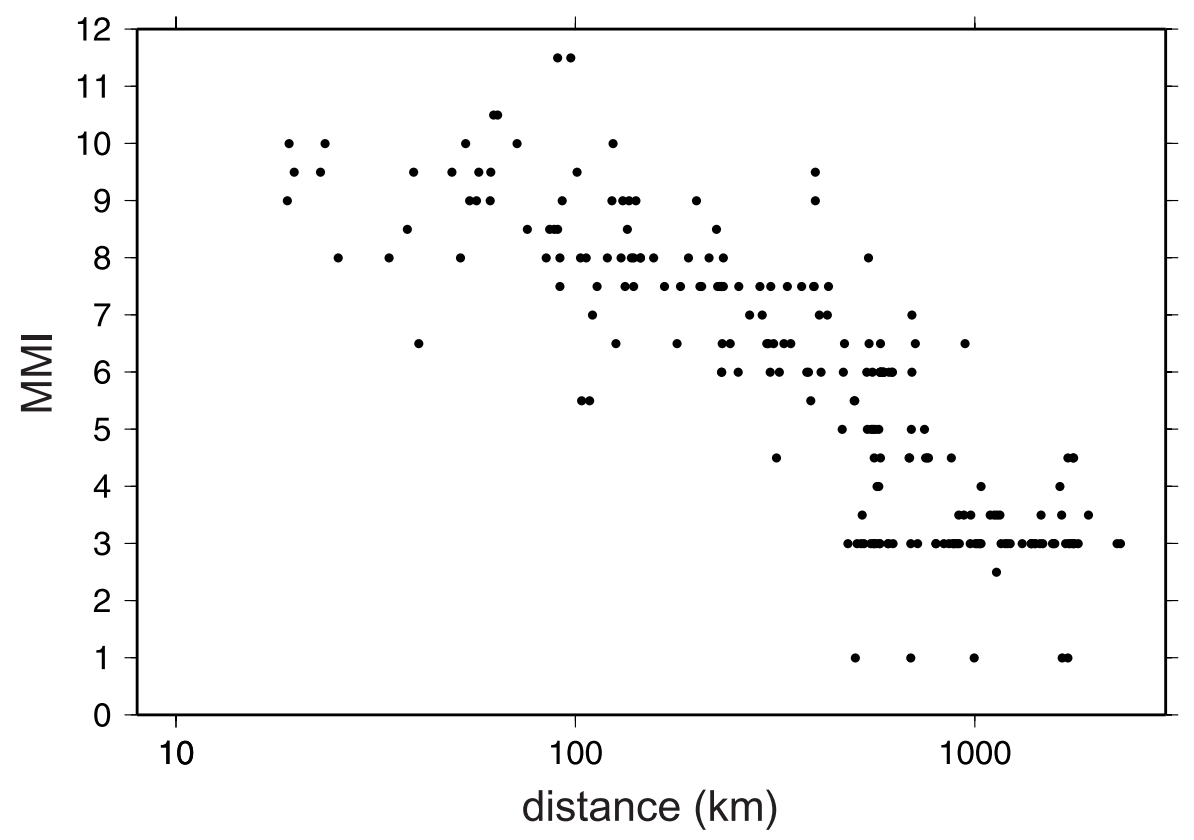

Figure 2. Inferred MMI values for the Bhuj earthquake are shown as a function of distance from the source. To estimate source distance, we calculate the nearest distance from each point to the "pseudo-fault" shown in figure 1.

surface (Bendick et al 2001). The estimated moment-magnitude, $M$, ranges from 7.5-7.7, nominally suggesting a rupture of $15-30 \mathrm{~km}$ width, 50-100 km length, and average slip of $1-4 \mathrm{~m}$. Preliminary results from aftershock studies indicate that the rupture was no shallower than about 8-9 km. Some of these parameters are modified, however.

We increase the dip from 33 to 36 degrees in the light of aftershock results suggesting that the rupture extended to a depth of $35 \mathrm{~km}$ (Horton et al 2001). We also shorten the rupture length to $50 \mathrm{~km}$ and use a fault depth of $9 \mathrm{~km}$ based on the preliminary analysis of geodetic data. Finally, we use a smooth rupture model in which the average slip is determined from the moment and fault area. We calculate ground motions for hard rock site conditions $(\kappa=0.005$; shear-wave velocity $=$ $3.7 \mathrm{~km} / \mathrm{sec}$ ) and will consider the issue of site response separately. No crustal amplification is applied to the predictions. For our attenuation model we use the results of Singh et al (1999) for Lg attenuation in India: $Q=508 f^{0.48}$. We use a geometrical spreading function that includes a $r^{-1}$ decay from 0 to $50 \mathrm{~km}$ and a $r^{-0.5}$ decay beyond $50 \mathrm{~km}$.

In the Beresnev and Atkinson (1997) approach, a rupture is simulated using fault plane subelements, each of which is treated as a point-source with a spectral shape constrained to have an $\omega^{2}$ shape. The method is attractive for this application because of its computational ease and because there are few model parameters to be assigned. It is limited in its ability to model the time-domain characteristics of low-frequency ground motions, but we consider it likely that the damage from the Bhuj earthquake is primarily controlled by relatively high-frequency shaking.

The most important free parameters in this method is the "strength parameter," $S_{f}$, which is related to the maximum slip velocity, $v_{m}$, according to

$$
v_{m}=0.618 y(\Delta \sigma) S_{f} /(\rho \beta),
$$

where $\beta$ is the shear wave velocity, $y$ is the rupture propagation velocity as a fraction of $\beta, \Delta \sigma$ is the sub-event stress-drop, and $\rho$ is density (Beresnev and Atkinson 2001). As discussed by Beresnev and Atkinson (2001), the amplitude of high-frequency radiation depends strongly on $S_{f}$. $S_{f}$ was found to vary between 1.0 and 2.4 for a wide range of earthquakes in eastern and western north America. In our application, the depth of faulting is another unknown. We therefore calculate peak ground acceleration (PGA) for a suite of possible rupture models with varying depths and strength parameters. We vary the depth to the upper edge of the rupture between 1 and $8 \mathrm{~km}$ and vary the strength factor between 1.2 and 2.4. The predicted ground motions are more sensitive to the strength factor than to depth. Unfortunately, it is difficult to constrain the strength parameter (or, equivalently, the slip velocity.) For north America, its average value is 1.6 . We find that a strength factor close to this value (1.8) predicts a PGA of $10 \% \mathrm{~g}$ at the distance of Ahmedabad, consistent with the single strong motion recording that was released 


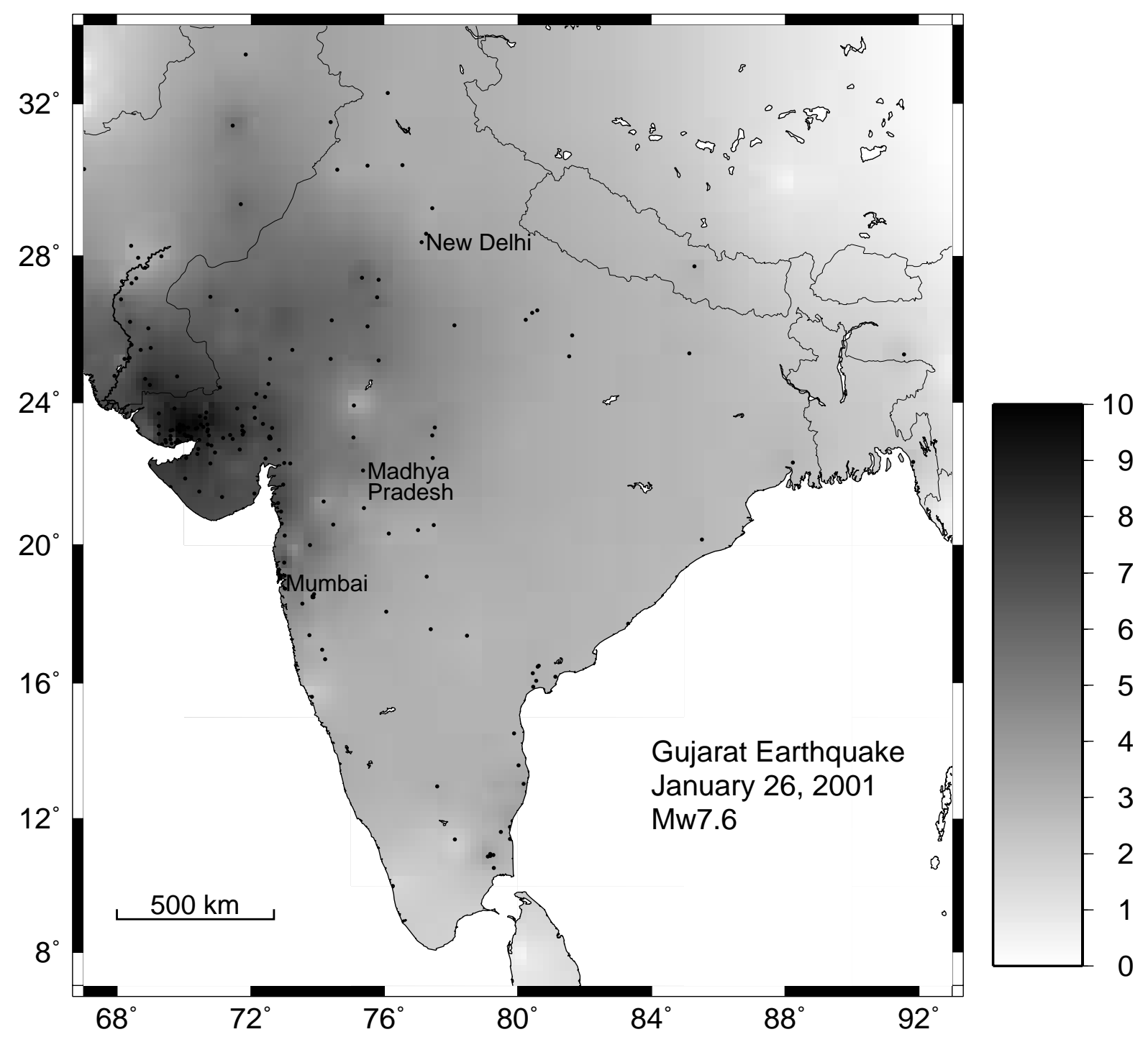

Figure 3. Map of intensity distribution for the 2001 Bhuj earthquake determined using a smoothing parameter of 1.0. MMI values are constrained at approximately 200 locations indicated with small circles. Gray scale reflects MMI values according to scale shown at right. Colour versions of these maps, which illustrate the intensity distribution more clearly, are available on-line, at http://pasadena.wr.usgs.gov/office/hough).

in the aftermath of the earthquake (figure 5). We therefore provisionally adopt this as our preferred strength factor value.

To compare predicted and estimated intensities, we convert predicted PGA to MMI using the calibration established by Wald et al (1999). It should be borne in mind that PGA (and thus MMI) is predicted for rock sites, and that MMI on soil will be as much as 1-2 units larger than on rock (Hough et al 2000; Atkinson 2001). Although it is clearly difficult to compare data and models in cases where both are uncertain, we find that the predicted ground motions are able to match several salient features of the shaking distribution determined from MMI data. In both data and models we find the highest shaking to the north and northwest of the epicenter and relatively low shaking to the southwest of the epicenter, as shown in figure 6. For a wide range of strength factors, the model corroborates the macroseismic observation that potentially damaging ground motions can occur at distances of at least several hundred $\mathrm{km}$ from the source. That is, peak ground accelerations on the order of $5 \% \mathrm{~g}$ generally correspond with the threshhold of damage (e.g., Wald et al 1999). Because site response at soil sites can typically elevate MMI values by one to two units (e.g., Hough et al 2000; Atkinson 2001), the predicted ground motions shown in figure 6 are high enough to cause damage, at soft-sediment sites especially, over the extent of the MMI IV region in these figures.

The residuals between observed intensities and those predicted on rock, are also interesting to con- 


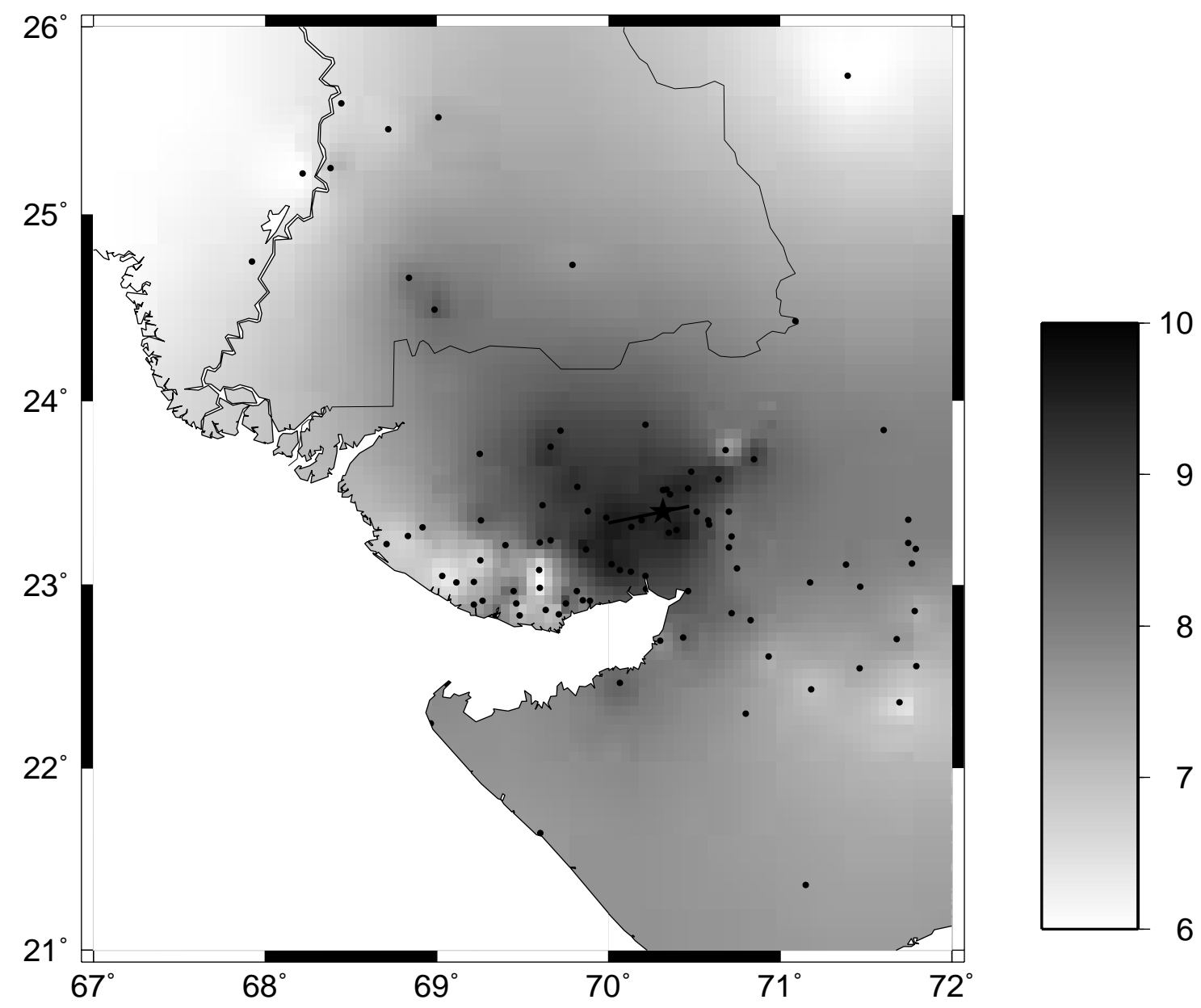

Figure 4. Close-up view of intensity distribution in the Kachchh region. Note that a different scale is used for intensities than that used in figure 3.

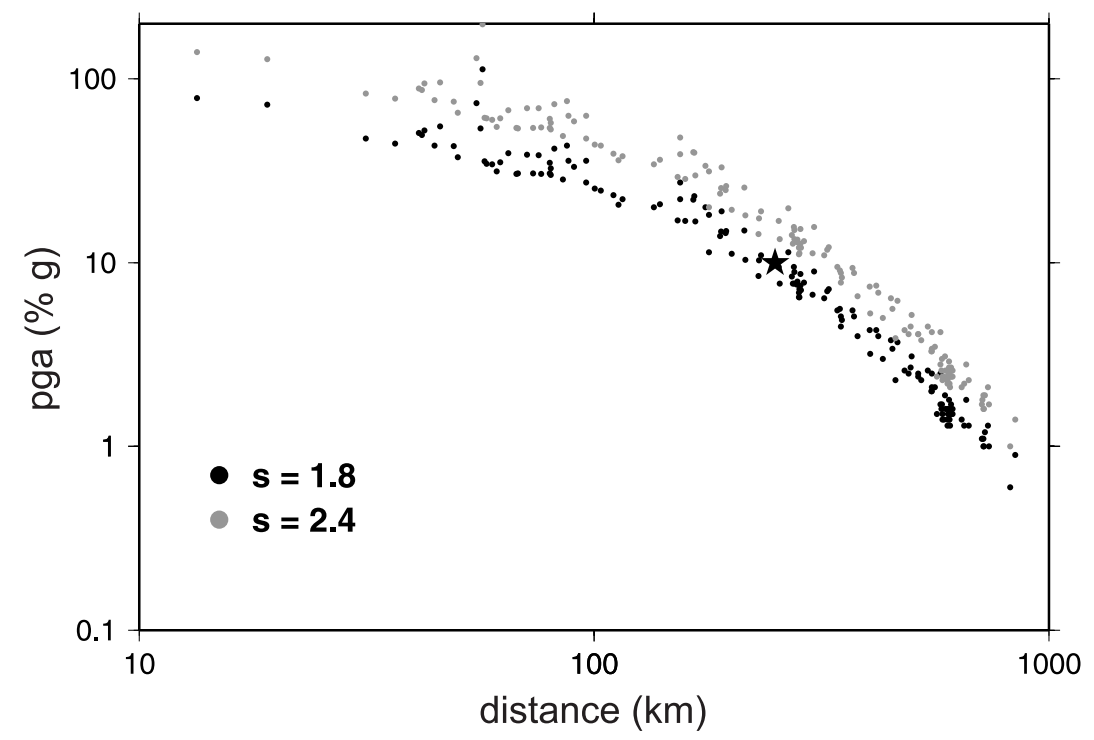

Figure 5. Peak ground acceleration values predicted on rock by the finite-fault model of Beresnev and Atkinson (1997) for strength factors of 1.8 (dark circles) and 2.4 (gray circles). Star indicates observed hard-rock peak acceleration observed at Ahmedabad. 


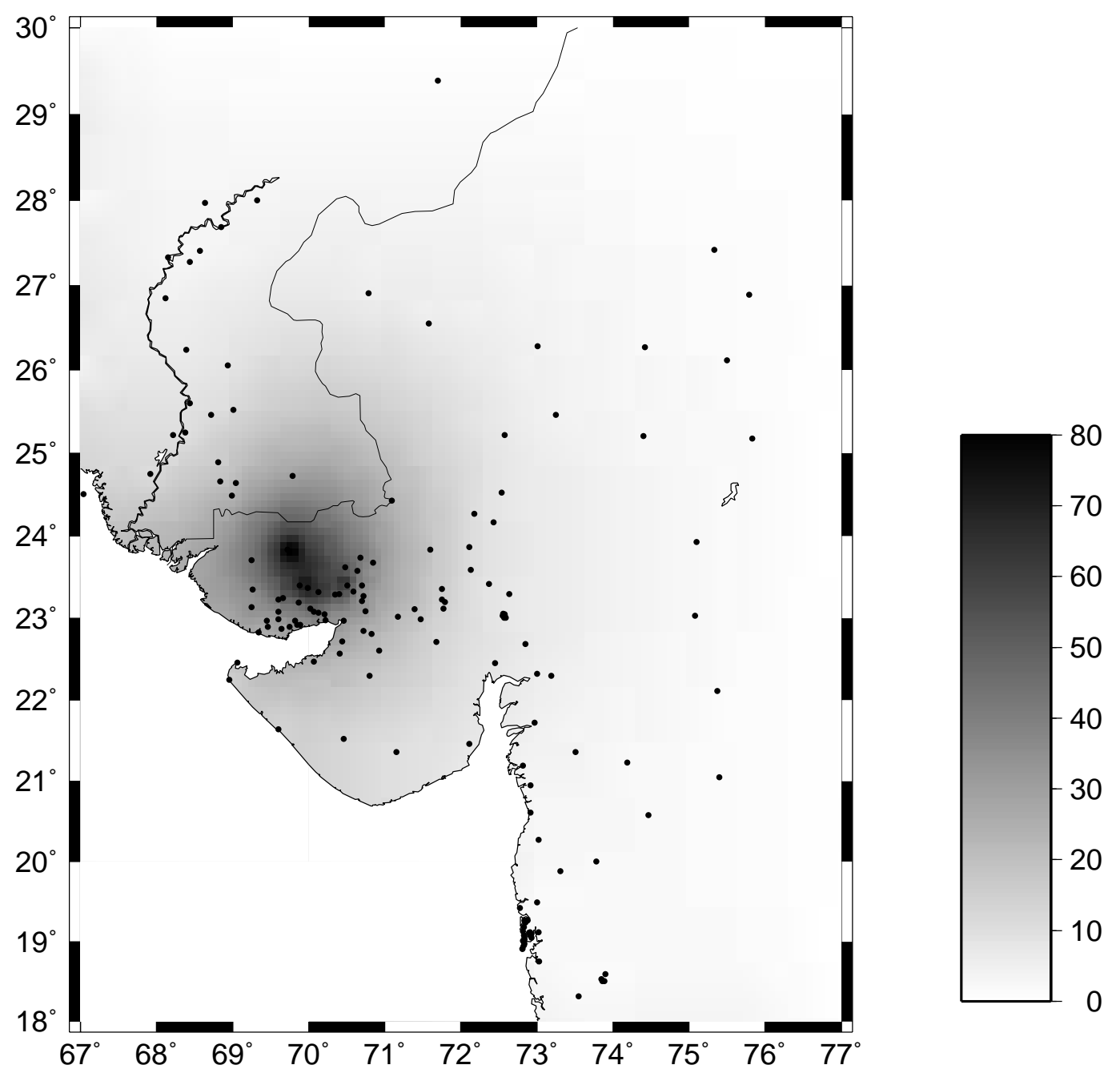

Figure 6. Predicted ground motions on rock for models with strength factor of 1.8. Note that intensities on soil would be 1 to 2 units higher. Note also that the scale is not the same as that used in figure 3, and indicates peak accelerations rather than intensity.

sider. We calculate residuals using ground motion predictions determined for $S_{f}=1.8$, and find that most values are between 1 and 2 MMI units. The distribution of residuals is generally consistent with expectations for site response, as especially high residuals are found at presumed sediment sites to the northeast and southeast of the rupture. Relatively low residuals are also found at locations to the southwest, which lie on the Deccan lavas.

A coherent band of low residuals is also observed along the Indus River in Pakistan. Regional geologic maps indicate that these sites should be alluvial. However, we speculate that the relatively low ground motions in this region may reflect path rather than site effects. That is, the active plate boundary west and northwest of Gujarat will likely disrupt coherent $L g$ wave propagation, which will give rise to a higher apparent attenuation and lower intensities (Kennett 1989; Hanks and John- ston 1992). Considering the spatial distribution of residuals, we speculate that the true regional attenuation curve might be steeper than that predicted by that of Singh et al. (1999). appropriate for $L g$ waves for this particular earthquake.

Within $100 \mathrm{~km}$ of the fault, however, ground motions estimated from our MMI values are systematically higher than those predicted by the model, typically by $1-2$ units. It is possible that most of this discrepancy is due to site response, which will tend to increase MMI on soil sites by at least one unit relative to that on rock sites. Other factors that may also be important are:

- the vulnerability of local buildings to shaking, and

- a tendency for media accounts to focus on the most extreme damage in hard-hit regions, especially in large cities, and

- the nature of the ground motions in an intraplate region. 


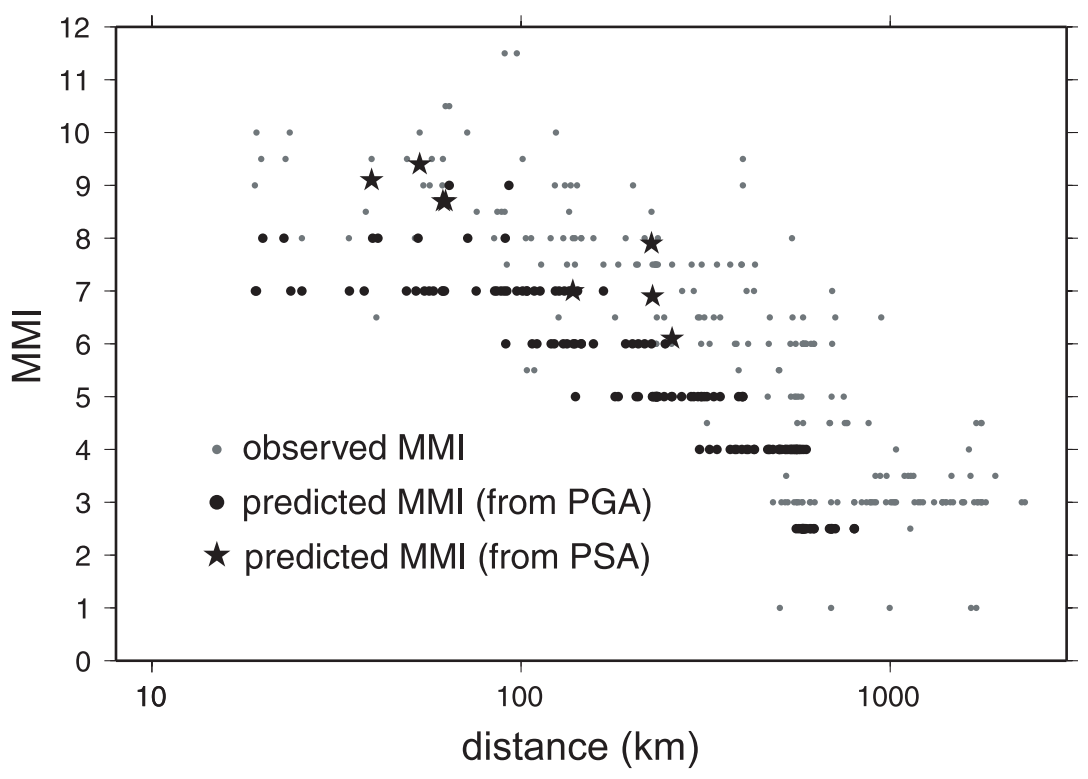

Figure 7. Our MMI values for the Bhuj earthquake are shown as a function of distance (small gray circles) along with predicted values calculated using a MMI-PGA relationship (large black circles) and one between MMI and response spectra (black stars).

It is difficult to estimate the bias contributed by each effect. However, we consider it unlikely that moderate estimated MMI values (IV-VI) are significantly amplified because of building vulnerability because these values reflect light damage (cracking of walls) and other effects (objects being knocked off shelves) that should not depend strongly on building type. It therefore appears likely that the other two factors account for more of the unit discrepancy, at least at close distances. Because news accounts generally focus on the most extreme rather than the typical damage in a region, it is not surprising that MMI values derived from media accounts will be systematically higher than those determined from average effects, in the manner employed by the Wald et al (1999) study.

One must also consider the possibility that a PGA-MMI relationship determined for earthquakes in California is not appropriate for an intraplate region. In particular, it has been suggested that because intraplate ground motions are generally characterized by a higher level of highfrequency energy, they might be more damaging (to some types of structures especially) than comparable earthquakes in interplate regions (e.g., Greig and Atkinson 1993; Atkinson 2001). To test this possibility, we recalculate predicted MMI values for a small number of locations using relationships between MMI and response spectra determined by Atkinson and Sonley (2000). These relationships are also determined for earthquakes in California. However, Atkinson (2001) validates their applicability in intraplate regions using the 1988 Saguenay earthquake, and argues that the relationships are generally appropriate because frequency content is handled explicitly. Figure 7 presents the MMI results determined from both PGA and response spectra, both on rock, and shows that the latter are indeed higher than the former. On an average, the MMI values are increased by approximately 1 unit when the response spectra relations are used. If one considers the expected influence of site response, the MMI predicted from response spectra are in reasonably good agreement with the observations.

\section{Implications for the 1819 Allah Bund earthquake}

The 1819 Allah Bund earthquake in the northern Rann of Kachchh was discussed at length by Oldham (1926) in one of his last important contributions. His interest in this event was initially stimulated by his efforts to complete his father's account of Indian earthquakes (Oldham 1883) and by the discovery of Baker's profile (Baker 1846) during a clean-out of the Bombay office of the Geographical Journal of Bombay in 1896. Baker's profile across the Allah Bund had been accidentally omitted by the editor from his narrative describing surface deformation but forms the basis of subsequent surface rupture parameter estimation by Bilham (1998).

Oldham collated newpaper reports of the 1819 event to produce an isoseismal contour map. This map was used by Richter (1958) to produce one of the first magnitude estimates for the event. His magnitude, 8.0, was derived from a comparison 


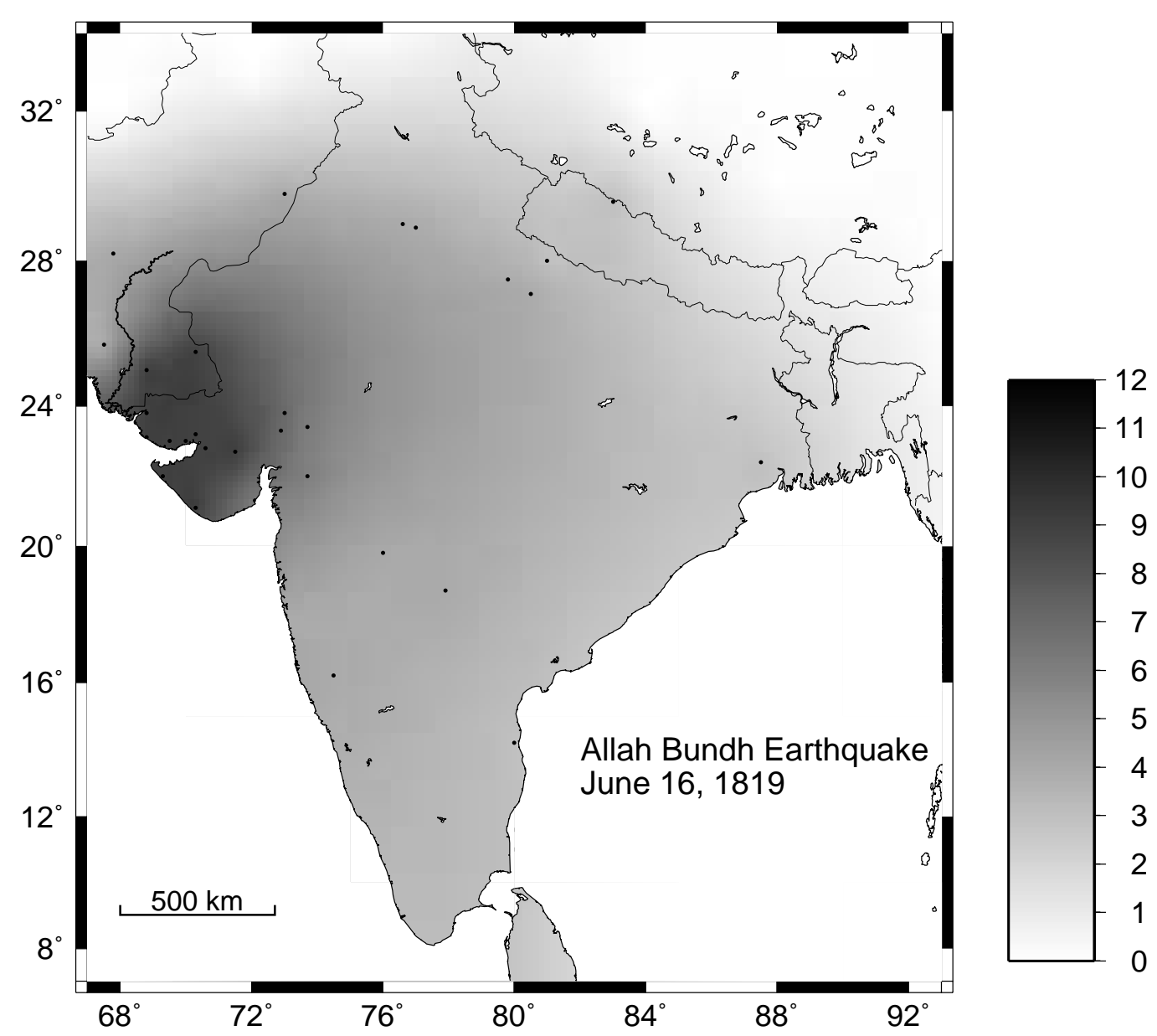

Figure 8. Distribution of shaking effects from the 1819 Allah Bund earthquake, from Bilham (1999) compared to those determined in this study for the 2001 Bhuj earthquake.

of the felt areas of the 1819 event with those of the 1905, 1934, and 1950 Indian earthquakes for which he had derived surface wave magnitudes. Recent recalibrations of these magnitudes suggest that many are inflated (Ambraseys and Bilham 2000; Chen and Molnar 1983).

Attempts to quantify the magnitude of the 1819 event from Oldham's isoseismal data were subsequently attempted by Johnston and Kanter (1992) and by Bilham (1998). Magnitude estimates varied from 7.6-7.9. A geologic estimate of the magnitude has been proposed by Rajendran and Rajendran (2001) based on the estimated rupture length and a surface slip estimate of $3 \mathrm{~m}$. Bilham (1998) used Baker's profile to derive a geodetic moment magnitude of $7.7 \pm 0.2$

The 2001 Bhuj earthquake stands to provide important new constraint on the magnitude of the 1819 event in that the mechanisms and locations of the two events are very similar. In many cases, local construction practices have not changed. In some cases, the same historic structures were damaged by both events (e.g., the forts and town walls of Bhuj and Anjar). Yet there are important differ- ences in that some earthquake resistant structures have been built in recent years; also, no concrete frame buildings existed in 1819 .

A detailed intensity map for the 1819 earthquake is unavailable. However, Bilham (1998) does map out sites that experienced severe and light damage, as well as sites at which the event was reportedly felt. We make crude MMI assignments of IX, VI, and III for these shaking levels, respectively (figure 8). A comparison of the isoseismal distribution of the 1819 and 2001 earthquakes shows that they are virtually indistinguishable in overall characteristics. Both events were felt lightly on the eastern coast of India; both caused light damage to distances of 500-600 km; and both caused heavy damage to distances of approximately $100 \mathrm{~km}$ (figure 8). (The extent of the high-intensity region is larger for the 1819 earthquake than it is for the Bhuj earthquake but we attribute this to the sparsity of the 1819 data and our inability to assess precise MMI values for each site where "severe" damage occurred.)

We therefore conclude that the magnitude of the 1819 Allah Bund earthquake was also likely to have 
been very close to 7.6. This value is within the uncertainties of previous estimates, but suggests that rupture dimensions and/or slip in 1819 may have been somewhat smaller than the values permitted by the higher geologic and geodetic estimates.

\section{Discussion and conclusions}

We have compiled media-based intensity maps for the January 26th, 2001, Bhuj earthquake. These maps, based only on news accounts of the event, allow us to map out the general distribution of shaking effects; they will also ultimately provide insight into the potential biases associated with determination of intensities based solely on media accounts. Such results are expected to be very useful, as the 2001 Bhuj earthquake has important implications for earthquake hazard in not only India, but also in other parts of the world where the source zones and/or the wave travel paths are similar. Based on our results and the similarity between their intensity distributions, we conclude that the 1819 Allah Bund earthquake had a magnitude very close to that of the 2001 Bhuj event: $7.6 \pm 0.1$.

Our results show that, especially in the absence of modern instrumentation, MMI data can provide important information about the distribution of ground motions. As discussed earlier, site response patterns are quite evident in the intensity distribution at both near and far distances. The overall felt distribution of the event also provides insights into the nature of $L g$ wave propagation. Hanks and Johnston (1992) showed that the far-reaching effects of central/eastern U.S. earthquakes can be explained by the efficient propagation of $L g$ waves (i.e., higher mode surface waves) within cratonic north America. Kennett (1989) showed that $L g$ waves will propagate efficiently within a waveguide, but will be disrupted when they encounter complexity such as crustal thickening. The felt area of the Bhuj earthquake is contained almost entirely within the Indian subcontinent. Our results therefore provide observational confirmation of the modeling results of Kennett (1989), that $L g$ waves are significantly disrupted by large-scale crustal complexity.

Our finite-fault modeling results show that our estimated MMI values provide a good indication of the distribution of ground motions (peak ground acceleration). Although the predicted hard-rock shaking level is lower than that inferred from macroseismic observations, we conclude that site response can explain most of the discrepancy. We have discussed three additional possible factors that might also contribute to the discrepancy:
- extreme vulnerability of buildings in the Kachchh region,

- a tendency of news accounts to focus on the most dramatic damage, and

- the nature of the ground motions in intraplate crust.

Although the first factor has been widely discussed, it is unlikely to account for the discrepancy in regions that experienced moderate (MMI IV-VI shaking). We also note that the discrepancy is no larger in the epicentral region than at regional distances, which perhaps suggests that building vulnerability was not an important factor at close distances. This would not be an altogether surprising result, as building type and vulnerability are taken into account when MMI values are assigned.

At present it is difficult to assess the effect of a possible "media bias," although we consider it likely that such a bias did contribute to the discrepancy. A comparison with a survey-based intensity map will ultimately allow us to constrain the magnitude of this effect. This result will have implications for the interpretation of historic earthquakes for which the only available information is from printed media sources.

The final possibility, that the Bhuj ground motions were unusually damaging because of their high levels of high-frequency energy, is interesting to consider. To compare predicted and estimate MMI values we have used a relationship between MMI and peak ground acceleration determined from recent large earthquakes in California. However, it has been suggested that ground motions from large intraplate earthquakes might be more damaging than their interplate counterparts (e.g., Greig and Atkinson 1993; Atkinson 2001). We therefore also compared predicted and estimated MMI values using a relationship between MMI and response spectral amplitudes (Atkinson and Sonley 2000). Although also developed for California earthquakes, Atkinson (2001) concludes that the relationship is appropriate for earthquakes in eastern north America, at least for distances of $150 \mathrm{~km}$ or less. Our results show that using the response spectral regressions, our predicted ground motions imply rock MMI values approximately one unit higher than those estimated from the MMI-PGA relationship. For soil sites, the predicted MMI values would be about 1 unit higher than for rock sites. Thus there would be no significant discrepancy between observed and predicted MMI values.

Although much work remains to be done, the Bhuj earthquake provides important information to better understand the hazard posed by earthquakes that occur in and/or affect intercratonic regions. In addition to insights into the nature of source zones in low strain-rate environments, the event provides invaluable new information 
with which the ground motions from past and future large intracratonic earthquakes can be better understood.

\section{Acknowledgments}

We thank Kali Wallace and Martitia Tuttle for helpful comments and suggestions that greatly improved the manuscript; maps were generated using GMT software (Wessel and Smith 1991). Research by S. Martin was supported by the Southern California Earthquake Center. SCEC is funded by NSF Cooperative Agreement EAR-8920136 and USGS Cooperative Agreements 14-08-0001-A0899 and 1434-HQ-97AG01718.

\section{References}

Ambraseys N and Bilham R 2000 A note on the Kangra $M_{s}=7.8$ earthquake of 4 April 1905; Current Science $\mathbf{7 9}$ 101-106

Atkinson G M 2001 Linking historical intensity observations with ground motion relations for eastern north America; Seism. Res. Lett. (submitted)

Atkinson G and Sonley E 2000 Empirical relationships between modified Mercalli intensity and response spectra; Bull. Seism. Soc. Am. 90 537-544

Baker W E 1846 Remarks on the Allah Bund and on the drainage of the eastern part of the Sind basin; Trans. Bombay Geogr. Soc. 7 186-188

Bendick R, Bilham R, Fielding E, Gaur V K, Hough S E, Kier G, Kulkarni M N, Martin S, Mueller K and Mukul M 2001 The January 26, 2001 Bhuj, India earthquake; Seismol. Res. Lett. 72 328-335

Beresnev I A and Atkinson G M 1997 Generic finite-fault model for ground-motion prediction in eastern North America; Bull. Seism. Soc. Am. 89 608-625

Beresnev I A and Atkinson G M 2001 Source parameters of earthquakes in eastern and western North America based on finite-fault modeling; Bull. Seism. Soc. Am. (submitted)

Bilham R 1998 Slip parameters for the Rann of Kachchh, India, 16 June 1819, earthquake, quantified from contemporary accounts; In: Coastal Tectonics, (eds) I S Stewart and C Vita-Finzi (London: Geological Society) 146 295318

Chen W P and Molnar P 1983 Focal depths of intracontinental and intraplate earthquakes and their implications for the thermal and mechanical properties of the lithosphere; J. Geophys. Res. 88 4183-4214
Greig G and Atkinson G 1993 Damage potential of eastern North American earthquakes; Seism. Res. Lett. 64119 137

Hanks T C and Johnston A 1992 Common features of the excitation and propagation of strong ground motion for North-American earthquakes; Bull. Seism. Soc. Am. $\mathbf{8 2}$ $1-23$

Hough S E, Armbruster J G, Seeber L and Hough J F 2000 On the modified mercalli intensities and magnitudes of the 1811-1812 New Madrid, Central United States earthquakes; J. Geophys. Res. 105 23,869-23,864

Horton S, Bodin P Johnston A, Withers M, Chiu C, Raphael A, Rabak I, Maio Q, Smalley R, Chiu J and Langston C 2001 Source characteristics of aftershocks of the India Republic Day earthquake (abstract); Trans. Am. Geophys. U. $\mathbf{8 2}$

Johnston A C and Kanter L R 1992 Stable continental earthquakes; Sci. Am. 262 68-75

Kennett B L N 1989 Lg-wave propagation in heterogeneous media; Bull. Seism. Soc. Am. 79 860-872

Oldham T 1883 Catalog of Indian earthquakes; Mem. Geol. Surv. India. 19 163-215 (Calcutta: Geol. Surv. India)

Oldham R D 1926 The Cutch (Kachh) Earthquake of 16th June, 1819 with a revision of the great earthquake; of 12th June, 1897; Mem. Geol. Surv. India 46 $71-146$

Rajendran C P and Rajendran K 2001 Character of deformation and past seismicity associated with the 1819 Kutch earthquake, northwestern India; Bull. Seism. Soc. $A m$. (in press)

Richter C F 1958 Elementary Seismology, (New York: W.H. Freeman)

Singh S K, Ordaz M, Dattatrayam R S and Gupta H K 1999 A spectral analysis of the 21 May 1997, Jabalpur, India, earthquake $\left(M_{w}=5.8\right)$ and estimation of ground motion from future earthquakes in the Indian shield region, Bull. Seism. Soc. Am. 89 1620-1630

Stover C W and Coffman J L 1993 Seismicity of the United States, 1568-1989 (revised); U.S. Geol. Surv. Prof. Pap. 1527

Tuttle M, Johnston A, Patterson G, Tucker K, Rajendran C P, Rajendran K, Thakkar M and Schweig E 2001a Liquefaction induced by the 2001 Republic Day Earthquake, India; Seism. Res. Lett. 72 p397

Tuttle M, Hengesh J V and Lettis W R 2001b Observations and comparisons of liquefaction features and related effects induced by the Bhuj Earthquake; Earthq. Spectra (submitted)

Wald D J, Quitoriano V, Heaton T H and Kanamori H 1999 Relationships between peak ground acceleration, peak ground velocity, and modified Mercalli intensity in California; Earthq. Spectra, 15 557-564

Wessel P and Smith W H F 1991 Free software helps map and display data; Eos Trans. AGU $\mathbf{7 2}$ 441, 445

Yagi and Kikuchi http://wwweic.eri.u-tokyo.ac.jp/yuji/ southindia/index.html 2001 